\title{
First Look at the Occurrence of Horizontally Oriented Ice Crystals over Summit, Greenland
}

\author{
Sebastian Cole ${ }^{1}$, Ryan R. Neely III ${ }^{1,2}$, Robert A. Stillwell ${ }^{3}$ \\ ${ }^{1}$ School of Earth and Environment, University of Leeds, Leeds, LS2 9JT, UK \\ $5 \quad{ }^{2}$ National Centre for Atmospheric Science, University of Leeds, Leeds, LS2 9JT, UK \\ ${ }^{3}$ Department of Aerospace Engineering Sciences, University of Colorado, Boulder, CO, 80309, USA
}

Correspondence to: Ryan R. Neely III (r.neely@leeds.ac.uk)

Abstract. The microphysical properties of clouds play a significant role in determining their radiative

10 effect; one of these properties is the orientation of ice crystals. A source of error in current microphysical retrievals and model simulations is the assumption that clouds are composed of only randomly oriented ice crystals (ROIC). This assumption is frequently not true, as evidenced by optical phenomena such as parhelia (commonly referred to as sundogs). Here, observations from the Cloud, Aerosol and Polarization Backscatter Lidar (CAPABL) at Summit, Greenland are utilized along with

15 instruments that are part of the Integrated Characterization of Energy, Clouds, Atmospheric state and Precipitation at Summit (ICECAPS) project in order to determine when, where and under what conditions horizontally oriented ice crystals (HOIC) occur at Summit, Greenland. Between July 2015 and May 2016, HOIC are observed on 86 days of the 335-day study. HOIC occurred within stratiform clouds on 48 days, in precipitation on 32 days and in cirrus clouds on 14 days. Analysis of all of the

20 cases found that, on average, in comparison to ROIC, HOIC occur at higher temperatures, higher wind speeds and lower heights above ground level. Differences were also present in the relative humidities (RHs) at which HOIC and ROIC occurred in stratiform clouds and precipitation but not in cirrus clouds. Analysis over the whole study period revealed monthly variations in the abundance of HOIC with the number of detections peaking in April and October. Monthly changes were also present in the number

25 of days containing HOIC. The results presented here aim to be the first step towards a comprehensive climatology and understanding of the microphysical processes that lead to the formation of HOIC at Summit, Greenland. 
Atmos. Chem. Phys. Discuss., doi:10.5194/acp-2016-1134, 2017

\section{Introduction}

The influence of clouds on the surface energy budget (SEB) is referred to as cloud radiative forcing (CRF). Clouds act to warm the surface by emitting longwave radiation but also to cool it by reflecting incoming shortwave radiation. CRF depends directly upon the cloud micro- and macrophysical

5 properties. This list of properties includes optical depth, fraction, phase and temperature as well as the solar zenith angle and underlying surface albedo and temperature (Ramanathan et al., 1989; Curry and Ebert, 1992; Corti and Peter, 2009; Bennartz et al., 2013; Cox et al. 2014). In the polar regions, CRF generally warms the surface, except in the summer when the maximum solar zenith angles are achieved and the surface albedo is at a minimum (Curry and Ebert 1992; Intrieri et al. 2002; Kay and L'Ecuyer, 10 2013; Miller et al, 2015), though Miller et al. (2015) found that over Summit, Greenland, unlike other sites, CRF always warms the surface, even in summer.

Since 1900, the Greenland Ice Sheet (GrIS) has contributed $\sim 25 \mathrm{~mm}$ to total global sea level rise (Kjeldsen 2015). The majority of this melting is due changes in the (SEB). Of the GrIS contribution to 15 sea level rise, CRF has enhanced the amount of meltwater by one-third (van den Broeke et al. 2009; de la Peña et al. 2015; Van Tricht et al. 2016). This general trend has also been punctuated by several extreme events, including July 2012 when the GrIS sustained the first melt event over the entire surface since 1889 (Neff et al. 2014).

20 Thus, understanding the factors that contribute to cloud optical depth are essential for understanding CRF. These factors include the vertical, concentration, phase, size and orientation of the constituent cloud particles (Curry and Ebert, 1992). Increased optical depth heightens cloud albedo, reflecting incoming solar radiation and also makes clouds more opaque to outgoing longwave radiation (Chen et al. 2000). Whether a cloud is composed of water, ice or both has a significant impact upon its radiative

25 properties (Shupe and Intrieri, 2004; Morrison et al. 2012). Sun and Shine (1994) found that the amount of radiation reflected from liquid clouds is between 2 and 4 times the amount reflected by ice clouds. An important influence of thermodynamic phase is also on cloud particle size. Ice crystals within a cloud are typically larger than liquid droplets (Shupe and Intrieri, 2004). This causes less surface area 
Atmos. Chem. Phys. Discuss., doi:10.5194/acp-2016-1134, 2017

per amount of water decreasing the overall optical depth unless otherwise compensated for by preferential orientation.

Although the relationship between size and concentration is significant in ice clouds, as it is in liquid

5 clouds, another important property exists that is specific to ice clouds. As liquid droplets are largely spherical, their interaction with radiation is the same regardless of the direction of incidence of the incoming radiation (Petty, 2004). Ice crystals lack the symmetry of water droplets. As a result of their asymmetry, the orientation of ice crystals significantly affects their interaction with incident radiation and therefore affects the radiative properties of clouds (Hirakata et al, 2014).

\subsection{Horizontally Oriented Ice Crystals (HOIC)}

It is well established that ice crystals often adopt a preferred orientation in the atmosphere which typically arises from drag forces encountered when falling (Whipple, 1940; Tricker 1970, Platt, 1978; Thomas et al., 1990; Takano and Liou, 1993, Klett, 1995; Westbrook et al., 2009, Westbrook, 2011). The preferred orientation of crystals tends to be that of its largest surface area being parallel to the

15 Earth's surface, thus its major axis assumes a horizontal position (Thomas et al, 1990; Westbrook et al, 2010). Although other habits of ice crystal, such as columns, have been known to adopt the same kind of preferred orientation (Thomas et al, 1990), HOIC are typically thought to take the form of hexagonal plates (Bréon and Dubrulle, 2004).

20 The presence of HOIC impact the surface energy balance by modulating CRF. HOIC can increase cloud albedo by as much as 40\% (Takano \& Liou, 1993; Hirakata et al., 2014). The higher albedo of clouds containing HOIC reflects more incoming shortwave radiation away from the Earth's surface (Sassen et al., 2003). Although the radiative effects of HOIC have been explored, only their impact on incoming shortwave radiation has been identified (Takano \& Liou, 1993; Hirakata et al., 2014). To the author's

25 knowledge, no observational studies have explored the implications of HOIC on longwave radiation though the anisotropic scattering of HOIC is well known (Takano, Y. and Liou, 1989; Hess and Wiegner, 1994). 
Atmos. Chem. Phys. Discuss., doi:10.5194/acp-2016-1134, 2017

Studies exploring HOIC have found significant differences in their frequency of occurrence even though ice crystal orientation is notoriously hard to detect from satellite observations (Noel and Chapfer, 2010). Chepfer et al. (1999) suggest that up to $40 \%$ of clouds contain HOIC globally. Chepfer

5 et al. (1999) used daytime only observations from the Polarization and Directionality of the Earth Reflectances (POLDER) instrument which precludes comprehensives studies of HOIC at the poles. Following up Chepfer et al. (1999), Bréon and Dubrulle (2004) found that POLDER observations to suggest that more than $50 \%$ of clouds contain HOIC. Again, as these observations were made using a passive instrument that is dependent on certain daytime conditions to make observations which

10 precludes a comprehensive study of HOIC over the poles. Interestingly, Thomas et al. (1990) found a similar fraction of cirrus clouds $(\sim 50 \%)$ to contain HOIC using a ground-based scanning lidar. This suggests that POLDER and other observations from space may be biased toward sampling only the fraction of cirrus clouds with HOIC.

15 The orientation of ice crystals specifically within Arctic clouds has only recently been explored. Noel and Chepfer (2010) considered HOIC in the Arctic in their global scale exploration of the occurrences of HOIC. The exploration of Noel and Chepfer (2010) however, only considers cirrus clouds. Using active remote sensing observations from the Cloud-Aerosol Lidar with Orthogonal Polarization (CALIOP), Zhou et al. (2013) showed a maximum occurrence of HOIC of $\sim 40 \%$ over the Arctic. In

20 addition, Zhou et al (2013) show that the occurrence of HOIC is strongly dependent on cloud temperature.

Yet, Zhou et al. (2013) relied on being able to separate populations of HOIC from other populations of ice crystals by comparing observations containing specular reflections with those that do not. Only

25 recent advancements in polarimetric active remote sensing have allowed for HOIC to be unambiguously (i.e. measuring a property exhibited solely by HOIC) identified with a single instrument (Kaul et al. 2004; Neely et al, 2013; Hayman and Thayer, 2012; Hayman et al. 2012). Neely et al (2013) utilize 
Atmos. Chem. Phys. Discuss., doi:10.5194/acp-2016-1134, 2017

these advancements to observe HOIC in Arctic as part of the Integrated Characterization of Energy, Clouds, Atmospheric state and Precipitation at Summit (ICECAPS) project (Shupe et al. 2013).

The importance of cloud microphysical properties on CRF is well established (Hirakata et al, 2014).

5 Given the vulnerability of the GrIS to CRF, a better understanding of the cloud microphysical properties is needed (Cawkwell \& Bamber, 2002). The lack of understanding in the area of CRF, particularly in the Arctic, is made prominent by the poor representation of CRF climate modelling (Cawkwell \& Bamber, 2002). Current simulations of climate and cloud radiative transfers rely on parameterizations of CRF (Noel and Chepfer, 2004). These parameterizations often make assumptions, a common

10 assumption being that the crystals within ice clouds are randomly oriented (Noel and Chepfer, 2004). As explored here, this is not always the case causing unknown bias in CRF projections and thus an unknown contribution to weather and climate parameters.

\section{Methods}

15 Summit, Greenland is located $3212 \mathrm{~m}$ above mean sea level on the GrIS at $72.6^{\circ} \mathrm{N}, 38.5^{\circ} \mathrm{W}$ (Neely et al, 2013; Shupe et al, 2013). In 2010, the ICECAPS project established an intensive cloud observatory at the station (Shupe et al. 2013). ICECAPS includes a wide range of instrumentation with the ability to capture turbulent and thermodynamic properties of the atmosphere and clouds. Specific instrumentation included in the ICECAPS suite be used as part of this study includes the Cloud Aerosol Polarization and

20 Backscatter Lidar (CAPABL), the NOAA Millimetre Cloud Radar (MMCR) and twice-daily radiosonde launches.

In this work we build upon the initial results of Neely et al. (2013), Shupe et al. (2013) and Stillwell et al. (2016) to examine the occurrence of HOIC over Summit, Greenland using CAPABL and supporting 25 observations. CAPABL was developed using the lidar polarisation theory of Hayman and Thayer (2012). To identify HOIC, CAPABL makes observations of diattenuation and depolarisation (Neely et al., 2013; Stillwell et al, 2016). HOIC exhibit both non-zero values of depolarisation and diattenuation when observed in a non-zenith/non-nadir orientation (non normal to the crystal face) while ROIC will 
Atmos. Chem. Phys. Discuss., doi:10.5194/acp-2016-1134, 2017

only exhibit non-zero values of depolarisation. For more information on how CAPABL implements the theory of Hayman and Thayer (2012) to make observations of HOIC please see Neely et al. (2013) and Stillwell et al. (2016). Using the measures of diattenuation and depolarisation ratio, CAPABL is the only instrument with the ability to unambiguously identify HOIC on an operational basis (Neely et al,

5 2013).

\subsection{HOIC Occurrence Categorization}

Though operational since 2010, only CAPABL data from July $2^{\text {nd }}, 2015$ was used because of hardware upgrades to the CAPABL that are fully described in Stillwell et al. (2016). The upgrades to CAPABL included a more powerful laser, an upgraded photomultiplier tube and most importantly a combined

10 analog and photo counting acquisition system. These upgrades have allowed for measurements to be made at a higher spatial and temporal resolution and with a better dynamic range (Stillwell et al. 2016). These improvements have allowed for CAPABL to observe the horizontal orientation of ice crystals in precipitation and have also improved observations in low, optically thick clouds and high clouds. The study period considers a 335-day period starting on July $2^{\text {nd }}, 2015$ and ending on May $31^{\text {st }}, 2016$.

15 Throughout this period CAPABL sampled at a temporal resolution of $5 \mathrm{~s}$ per polarisation and a spatial resolution of $7.5 \mathrm{~m}$. For an overall improved signal-to-noise ratio we have integrated this raw data to have a resolution of $30 \mathrm{~m}$ and $20 \mathrm{~s}$ ( 80 seconds for a complete 4 polarisation retrieval of diattenuation). Approximately 5 minutes of data per day was missed at midnight UTC to allow for system diagnostics (Stillwell et al., 2016). This time combined with other required maintenance over the study period 20 resulted in $\sim 8070$ hours of data with a $98.9 \%$ uptime (i.e. on average, only 16 minutes of data per day was lost). Observations from lower than $0.2 \mathrm{~km}$ above ground level (AGL) were disregarded in order to minimize the influence of HOIC in fog/diamond dust and blowing snow as well a systemic effects due to the overlap of CAPABL's laser and telescope (Stillwell et al., 2016). Observations from above $8 \mathrm{~km}$ AGL were also disregarded in accordance with the observations of Shupe et al. (2013) who found the

25 majority of clouds at Summit to occur beneath $8 \mathrm{~km}$. CAPABL is thus tuned to the range 0.2 to $8 \mathrm{~km}$ and has relatively poor signal strengths above this level. 
Atmos. Chem. Phys. Discuss., doi:10.5194/acp-2016-1134, 2017

Having established the temporal and spatial domain of the study, criteria was set in order to mask the data and identified the thermodynamic phase of clouds present and whether ice is horizontally oriented or not using the method outlined by Stillwell et al. (2016). Table 1 shows the specific criteria used in this study.

5

Depolarisation values set for the identification of liquid and ice is consistent with previous studies of Arctic clouds by Intrieri et al (2002), Shupe (2005) and Stillwell et al. (2016). Values of combined diattenuation were computed by multiplying CAPABL's two diattenaution observations together in order to remove false positives within the data as described in Stillwell et al. (2016). Thus, the 0.005

10 used in the diatentuation criteria here is slightly more stringent (i.e. $\sqrt{ } 0.005>.05$ ) than the value used by Neely et al. (2013). Error associated with CAPABL's observations of depolarization and diattenuation were quantified through the methods of Stillwell et al. (2016).

\subsection{Identification of Thermodynamic and Dynamic Atmospheric Conditions}

Values of temperature, RH and horizontal wind speed were obtained from twice-daily radiosonde

15 launches at Summit. Data for all variables from radiosondes were linearly interpolated to correspond to the resolutions of measurements made by CAPABL. From this, observations were linearly interpolated with time for each day, creating a grid with the same spatial and temporal domain as the CAPABL observations but containing radiosonde observations. For each day, the altitude and time of each occurrence of the atmospheric conditions were assigned the corresponding values of temperature,

20 relative humidity $(\mathrm{RH})$ and horizontal wind speed from the interpolated grid of radiosonde observations.

\subsection{Analysis of Temporal Variability}

The frequencies of HOIC occurrence were calculated using all available days for each month of the study period. Frequencies of occurrence $(\mathrm{F})$ of each atmospheric condition defined in Table 1 were

25 calculated for each month using Equation 1 where $\mathrm{N}$ denotes the number of detections identified as a result of the masking process for HOIC, ice and liquid, and $\mathrm{x}$ is either HOIC, ice or liquid interchangeably. 
Atmos. Chem. Phys. Discuss., doi:10.5194/acp-2016-1134, 2017

Manuscript under review for journal Atmos. Chem. Phys.

Discussion started: 16 March 2017

(c) Author(s) 2017. CC-BY 3.0 License.

$$
F_{x}=\frac{N_{x}}{N_{\text {HOIC }}+N_{\text {ROIC }}+N_{\text {Liq }}} \times 100
$$

The number of detections of each data type identified as a result of the masking process were summed in order to establish the total number of quality controlled measurements per month.

5 All days containing HOIC were explored and the nature of the occurrence was classified as cirrus, stratiform or falling/precipitating. These classifications were based on the vertical wind observations from the Doppler spectra measured by the NOAA MMCR. The role of liquid was not considered in the analysis of cirrus clouds as they are composed solely of ice crystals. Liquid was also not considered in the analysis of the falling/precipitating classification. Liquid droplets within Arctic clouds are too small

10 to be precipitated (Morrison et al, 2012). Having classified the occurrences of HOIC, the number of occurrences per classification was totalled. A day containing more than one classification was counted in each of the classifications within the day.

\section{Results}

15 Using the criteria in Table 1, HOIC were positively identified in cirrus clouds, stratiform clouds or precipitating from clouds on 86 days of the 335-day study period. Figure 1 shows an example product of the masking process applied to CAPABL's data on 20 February 2016 from 00:00 to 24:00 UTC.

\subsection{Case Study on 22 April 2016}

20 To illustrate the analysis process, we show a short period of observations form 22 April 2016. HOIC were observed on 3 occasions during this period. These occurrences were identified from the masking procedure (results shown in the middle panel of Figure 2) and inspection of the corresponding radar observations in Figure 2. At 16:00 there is substantial HOIC present and this has been separated into 3 distinct occurrences using the combination of CAPABL and NOAA MMCR observations shown in

25 Figure 2: 1) at 4km a large pocket of HOIC is identified in cirris, 2) in small deck of liquid bearing stratiform clouds at $1.5 \mathrm{~km}$ and 3 ) in precipitating ice near the surface. Following these occurences HOIC was also observed at 18:00 in precipitating/falling ice that is connected to the higher clouds. 
Atmos. Chem. Phys. Discuss., doi:10.5194/acp-2016-1134, 2017

Finally, at 20:00 and into the next day, the cirrus clouds at $4 \mathrm{~km}$ show a strong HOIC signal that is typical of HOIC in cirrus found on other days. This method is used throughout the study to broadly classify the type of HOIC occurrence.

5 Combining the HOIC mask with the information provided by interpolated radiosonde profiles bounding the observaiton period (for this example for profiles from 12Z on April 22, 2016 and 00Z on April 23, 2016 were used) we create a pixel by pixel comparison of the conditions in which HOIC compared to ROIC occurred througout the day. For this example, we have not broken this into the classifications of cirrus, striatiform or precipitating ice due to the limited sample size. From the boxplots of Figure 3 it

10 can be said the HOIC are occurring over a much smaller range of temperatures than ROIC, and a slightly higher temperature of $-25.4^{\circ} \mathrm{C}$ as opposed to the $-26.9^{\circ} \mathrm{C}$ of ROIC. The range of RH over which HOIC are occurring is much wider than that of ROIC. HOIC also has a higher median value of $57.2 \%$ compared to that of the ROIC, $51.2 \%$. The horizontal wind speeds over which both HOIC and ROIC occur are again different. HOIC occur over a much smaller range of wind speeds compared to HOIC.

15 HOIC also have a lower median horizontal wind speed of $18.5 \mathrm{~ms}^{-1}$ as opposed to $19.6 \mathrm{~ms}^{-1}$ of ROIC. Further differences can be seen in the height ranges of both ROIC and HOIC. ROIC occurred over a larger vertical range than HOIC, and typically occurred higher in the atmosphere with a median height of $1.45 \mathrm{~km}$, compared to the $0.96 \mathrm{~km}$ of HOIC.

20 Individual occurrences of HOIC were identified classified using daily sets of observations similar to Figure 2 and Figure 3. This information was then compiled over the whole study period and all cases were analysed together below.

\subsection{Temporal Variability in HOIC}

25 Analysis over the whole study period revealed a number of patterns in the presence of HOIC. Figure 4 shows the monthly frequency of occurrence of HOIC, ROIC and Liquid in clouds. January and December appear to have the highest frequencies of occurrence of HOIC with $8.1 \%$ in January and $6.3 \%$ in December. From July to November the percentage of observations considered to be HOIC 
Atmos. Chem. Phys. Discuss., doi:10.5194/acp-2016-1134, 2017

remains largely constant only varying by $0.3 \%$ between $0.7 \%$ in July and August and $1 \%$ in October. February and March see the lowest percentage of occurrence $0.3 \%$ and $0.6 \%$ respectively. April and May can be seen to have to frequencies closest to the average of the study period, with values of $1.7 \%$ and $1.4 \%$, the mean being $2.9 \%$. No clear relationship can be seen between the frequency of the total

5 occurrence in all observations of HOIC (i.e. not the fraction of observaitons containing HOIC) and, similarly, the frequencies of total occurrence of liquid and ice.

The monthly variability in the frequency of HOIC occurring in clouds does not correspond to the total number detections indicating the presence of HOIC. Figure 5 shows the number of pixels per month

10 containing HOIC and the category of the occurrence. From Figure 5 there appears to be a relatively uniform distribution with 2 outliers in the number of detections with peaks in the months of April and October. The number of detections is lowest in November, December and February.

Figure 6 show the total number of days, by occurrence type, that HOIC were detected in each month. A 15 likeness can be seen in the variations of total number of clouds, irrespective of cloud type, and the total number of detections by pixel in Figure 5. The differences between these two counting methods are seen in the outliers of the distributions which occur in May rather than April, and in September rather than October when counting the number of days with HOIC. Differences in the relative magnitudes of days against detections can be seen in January which has much lower numbers of days with

20 observations containing HOIC compared with the number of detections present in those months.

From Figure 5 and 6, indications of monthly variations in the type of cloud in which HOIC were observed are clear. Cirrus clouds containing HOIC were only found to occur between February and April. HOIC were observed most frequently in stratiform clouds in all months with the exception of

25 February, March and April. HOIC precipitating from clouds occurred mostly in the spring and autumn months, with only 1 occurrence in winter and 5 in summer compared with 16 in spring and 9 in autumn. 
Atmos. Chem. Phys. Discuss., doi:10.5194/acp-2016-1134, 2017

Figure 7 shows the ranges of height over which HOIC were observed for each month of the study period. With the exception of February, median heights of below $1 \mathrm{~km}$. The pattern of this distribution largely follows the distribution of occurrence type observed for the HOIC. The higher median of February corresponds to the 6 days on which HOIC were observed in cirrus clouds in Figure 6.

\subsection{HOIC in Cirrus Clouds}

On 14 days HOIC were identified in cirrus clouds. The distribution of conditions that allow for HOIC to occur in cirrus clouds above Summit are compared to those of ROIC and shown in Figure 8. Both $\mathrm{HOIC}$ and ROIC occurred over similar temperature ranges, $\mathrm{HOIC}$ between $-42^{\circ} \mathrm{C}$ and $-25^{\circ} \mathrm{C}$ and $\mathrm{ROIC}$

10 between $-44^{\circ} \mathrm{C}$ and $-27^{\circ} \mathrm{C}$. Despite the ranges being similar, the distributions within them vary between $\mathrm{HOIC}$ and ROIC, HOIC having a higher median temperature than ROIC; of $-28^{\circ}$ and $-34^{\circ} \mathrm{C}$ respectively. The range of RHs that HOIC occur over is slightly larger than that of ROIC but both ranges have an upper limit of $74 \%$ with lower limits of $51 \%$ for HOIC and 53\% for ROIC. The medians of RH are similar. HOIC was found to have a median RH of $62 \%$ compared to $65 \%$ of ROIC. The

15 spread of horizontal wind speeds over which both HOIC and ROIC occur are distinctly different. HOIC occur over a range of $7 \mathrm{~ms}^{-1}$ between $13 \mathrm{~ms}^{-1}$ and $20 \mathrm{~ms}-1$ with a median of $17 \mathrm{~ms}^{-1}$. ROIC occur over a range of 15.9 between $9 \mathrm{~ms}^{-1}$ and $16 \mathrm{~ms}^{-1}$ with a median of $11 \mathrm{~ms}^{-1}$. HOIC and ROIC were both predominantly observed below $3.5 \mathrm{~km}$ AGL. HOIC were observed over a wider range of heights than ROIC but at a lower median height of $1.43 \mathrm{~km}$. Table 2 shows the means and the statistical significance

20 of the variations seen in temperature, $\mathrm{RH}$, horizontal wind speed and height. Statistical differences between the means can be seen in all variables tested with the exception of RH.

\subsection{HOIC in Stratiform Clouds}

On 48 days HOIC were identified in stratiform clouds. Figure 9 compares the conditions allowing for

25 liquid, ROIC and HOIC to occur in stratiform clouds. The temperatures at which liquid, ROIC and $\mathrm{HOIC}$ were observed are largely similar. The median temperature of liquid was, $-17^{\circ} \mathrm{C}$, the warmest temperature compared to both HOIC and ROIC. Both ROIC and HOIC were seen to have the lower median temperatures than liquid of $-20^{\circ} \mathrm{C}$. 
Atmos. Chem. Phys. Discuss., doi:10.5194/acp-2016-1134, 2017

The RH ranges over which liquid, ROIC and HOIC can be seen in stratiform clouds are variable. The range $\mathrm{RH}$ range of liquid is between $80-93 \%$, a narrower range than that of HOIC and ROIC with ranges of $74-91 \%$ and $70-87 \%$ respectively. The median values of $\mathrm{RH}$ are not as variable with only $5.19 \%$ between liquid and ROIC; Liquid has a median value of $85 \%$, HOIC of $84 \%$ and ROIC, $80 \%$.

The horizontal wind speeds over which liquid, ROIC and HOIC were observed were also variable. HOIC were observed to occur at the highest median horizontal wind speed, $13 \mathrm{~ms}^{-1}$, and a range of 8 $\mathrm{ms}^{-1}$ between $9 \mathrm{~ms}^{-1}$ and $17 \mathrm{~ms}^{-1}$. ROIC occurred over the largest range of $7 \mathrm{~ms}^{-1}$ between $8 \mathrm{~ms}^{-1}$ and 15 $\mathrm{ms}^{-1}$, with a median of $11 \mathrm{~ms}^{-1}$. Liquid occurred over the same range of horizontal wind speeds but with 10 a higher median horizontal wind speed of $12 \mathrm{~ms}^{-1}$. The height ranges of all liquid, ROIC and HOIC are below $2 \mathrm{~km}$ AGL. Liquid has the smallest range of heights and the lowest median of $0.55 \mathrm{~km}$ AGL. ROIC has the largest range of heights between $0.29 \mathrm{~km}$ and $2.39 \mathrm{~km}$ and the highest median of $0.83 \mathrm{~km}$. HOIC has a larger range then liquid, between $0.23 \mathrm{~km}$ and $1.59 \mathrm{~km}$ and a median of $0.7 \mathrm{~km}$.

15 Table 3 shows the significance of differences between ROIC and HOIC in stratiform clouds. Differences between HOIC and ROIC can be seen in all variables tested. HOIC occurred at a slightly lower temperature, lower RH, marginally higher horizontal wind speed and occurred $260 \mathrm{~m}$ lower in atmosphere. Even though some of these differences are small, they are still statistically different due to the large number of data points used to create the distribution tested.

Table 4 shows the significance of differences between liquid and HOIC in stratiform clouds. For all variables tested differences emerged between liquid and HOIC. Comparing the mean conditions of HOIC and liquid, HOIC were present at a slightly lower temperature, lower RH, marginally higher horizontal wind speed and occurred 150m higher in atmosphere. Even though some of these differences

25 are small, they are again still statistically different due to the large number of data points used to create the distribution tested $(>50,000)$. 
Atmos. Chem. Phys. Discuss., doi:10.5194/acp-2016-1134, 2017

\subsection{Falling/Precipitating HOIC}

On 32 days HOIC were identified in precipitating from clouds. The conditions when HOIC and ROIC were observed to be falling from clouds are compared in Figure 10.The temperatures over which ROIC and $\mathrm{HOIC}$ were observed are very similar, ranging $-16^{\circ} \mathrm{C}$ to $-24^{\circ} \mathrm{C}$ and $-16^{\circ} \mathrm{C}$ to $-23^{\circ} \mathrm{C}$ respectively. The

5 median temperatures were found to be the same, $-20^{\circ} \mathrm{C}$. Precipitated ROIC was observed over a much wider range of RHs than HOIC; ROIC between 66-88\% and HOIC between 76-88\%. The medians of RH are more similar than their ranges, with ROIC with a median of $80 \%$ and $\mathrm{HOIC}, 84 \%$.

ROIC were seen to occur over range of horizontal wind speeds between $8 \mathrm{~ms}^{-1}$ and $19 \mathrm{~ms}^{-1}$. HOIC were

10 observed over a similar range but of higher horizontal wind speeds, from $11 \mathrm{~ms}^{-1}$ to $21 \mathrm{~ms}^{-1}$. The medians of horizontal wind speed vary by $5 \mathrm{~ms}^{-1}$; the median horizontal wind speed of HOIC being $17 \mathrm{~ms}^{-1}$ and the median of ROIC being $12 \mathrm{~ms}^{-1}$. Both height ranges of HOIC and ROIC are below $1.5 \mathrm{~km}$ AGL and both median values are below $1 \mathrm{~km}$ AGL. The median height of HOIC is $0.34 \mathrm{~km}$ AGL; lower than that of ROIC, $0.7 \mathrm{~km}$ AGL.

15

The significance of differences between the variables of Figure 9 were tested and are shown in Table 5. From Table 5, it is clear that differences are present; the temperature of precipitated HOIC is lower than that of ROIC, RH of HOIC is higher, horizontal wind speed is higher and height is lower. As the means of temperature were found to be the quite but a difference was identified between the datasets, a

20 histogram is presented in Figure 11. From Figure 11, the distributions of temperature seem to be similar, with most observations between $-10^{\circ} \mathrm{C}$ and $-25^{\circ} \mathrm{C}$. The temperatures at which ROIC are occurring are much more even in their distribution whereas HOIC have distinctive peaks. These peaks occur around $10^{\circ} \mathrm{C},-20^{\circ} \mathrm{C}$ and $-25^{\circ} \mathrm{C}$. The trend irrespective of these peaks, reaches a maximum around $-15^{\circ} \mathrm{C}$. The peaks in the occurrence of ROIC are less well defined, despite a peak at $-18^{\circ} \mathrm{C},-22^{\circ} \mathrm{C}$ looks to be 25 central in the distribution. 
Atmos. Chem. Phys. Discuss., doi:10.5194/acp-2016-1134, 2017

\subsection{Synthesis of Results}

From the results presented in Sections 4.1-4.5 a number of similarities emerge in the conditions allowing for HOIC to be present. The mean temperature of HOIC in all cases is higher than that of ROIC. This difference is also reflected in the median temperatures of the case study in Section 4.1 but

5 its significance here is not known. The temperatures at which HOIC occur within both stratiform clouds and precipitation is the same, $-20^{\circ} \mathrm{C}$, a much warmer temperature than $\mathrm{HOIC}$ in cirrus.

The mean RHs are higher for HOIC than they are for ROIC in all cases. The mean RHs are only different from those of ROIC in falling HOIC and stratiform clouds, not in cirrus. Like the temperatures of HOIC, the RHs of HOIC in stratiform clouds and precipitation are similar. The mean horizontal wind

10 speeds that HOIC occur under are always higher than those of ROIC. HOIC in cirrus were seen to occur at the highest mean horizontal wind speed of the 3 types of occurrence, $17 \mathrm{~ms}^{-1}$. Precipitated HOIC were found at a similar horizontal wind speeds of $16 \mathrm{~ms}^{-1}$ and HOIC in stratiform at a lower horizontal wind speeds. The mean heights of HOIC in all cases were always lower than that of ROIC and higher than liquid in stratiform clouds. The lowest mean height of HOIC was of precipitated/falling HOIC with

15 the mean height of HOIC in stratiform clouds being $0.2 \mathrm{~km}$ higher. HOIC in cirrus clouds were found to have the highest mean altitude of $2.13 \mathrm{~km}$.

Temporal variabilities in HOIC show the frequency of occurrence of HOIC (Figure 5 and Figure 6) to be highly variable. Seasonal variations in cloud type are also present, but due to the limited time over

20 which observations have been collected no large scale patterns may yet be deduced. In particular, HOIC in cirrus is only seen in February, March and April. In addition, the monthly height variations in Figure 7 largely agree with the amount of each classification of HOIC occurrence per month, shown in Figure 6. This correlation suggests that HOIC are present in all clouds and the conditions of their occurrence is primarily dependent on the predominant types of clouds present at any given time. 
Atmos. Chem. Phys. Discuss., doi:10.5194/acp-2016-1134, 2017

\section{Discussion}

\subsection{HOIC on 22nd April 2016}

The case study presented in Section 3.1 is largely representative of the mean values identified in the various cases. On two occurrences on the 22 April 2016, HOIC were observed precipitating from

5 clouds. Figure 10 show the median temperatures, RHs and heights of HOIC and ROIC to follow the same pattern. The median horizontal wind speed however does not comply with the mean horizontal wind speeds for HOIC identified for all HOIC cases in precipitated HOIC and HOIC in cirrus. The precipitated HOIC occurring at a lower horizontal wind speed than that of ROIC seems to accurately replicate the formation process of Shupe et al (2013). Whether the horizontal wind speed at which

10 HOIC is occurring in cirrus clouds is reflected in the median of Figure 8, which was computed from the linear interpolation of radiosondes launch every 12 hours, is hard to tell though the wind observations are most likely representative of the bulk flow at the height of cirrus clouds. If these observations serve as a good proxy for the wind experience by the observed clouds, the wind speeds at which HOIC are occurring within cirrus, in this case, are lower than that of ROIC. No clear explanation can be found

15 within the literature regarding the role of horizontal wind speed in the occurrence of HOIC within cirrus clouds. The theory of Sassen et al (2003) could be related to this, leaving HOIC in cirrus purely the result of temperature.

\subsection{Temperature Dependence of HOIC}

20 Noel \& Chepfer (2010) found HOIC occurring within the temperature range of $-30^{\circ} \mathrm{C}$ to $-10^{\circ} \mathrm{C}$. The results presented here are largely in agreement. All mean temperatures of HOIC with the exception of $\mathrm{HOIC}$ in cirrus clouds agree; a mean temperature of $-33^{\circ} \mathrm{C}$. Although the mean temperature of HOIC in cirrus does not fall within the range of Noel and Chepfer (2010), it does fall within the range of temperatures outlined by Zhou et al $(2013)\left(-40^{\circ} \mathrm{C}\right.$ to $\left.-20^{\circ} \mathrm{C}\right)$. Both of these ranges however coincide

25 with the range defined as the plate regime by Bailey and Hallet (2009). Even though differences occur between the temperatures of HOIC and ROIC, the mean temperatures of ROIC, with the exception of ROIC in cirrus, also fall within the plate regime of Bailey and Hallet (2009) and range of temperatures identified by Noel and Chepfer (2010). 
Atmos. Chem. Phys. Discuss., doi:10.5194/acp-2016-1134, 2017

Mean temperatures of HOIC and ROIC both being within the plate regime in all cases could suggest three things. Firstly, that temperature is important in determining differences within the plate regime of Bailey and Hallet (2009). Secondly, that temperature does not play a role outside of determining the

5 habit of ice crystals being formed and that other factors must be involved in determining their orientation given that plates exist.

Though the mean temperatures of both HOIC and ROIC are inside the temperature range of the plate regime, both HOIC and ROIC have been observed occurring outside of the plate regime, in the regime

10 of columns. The occurrence of HOIC at temperatures outside of the plate regime could mean that crystals of a columnar nature are also assuming a preferential orientation. It could also arise from poor resolution of sampling. If the radiosonde and CAPABL observations are not integrated well this could lead to erroneous temperature readings for HOIC.

15 The presence of HOIC within the temperatures range of the plate regime in stratiform clouds and precipitation is suggestive of the process outlined by Shupe et al (2013) and Westbrook (2010). Should this mechanism be taking place, it would suggest that HOIC tend to be dendritic in nature. Bailey and Hallet (2004) observed the growth of dendritic ice crystals at temperatures around between $-18^{\circ} \mathrm{C}$ and $20^{\circ} \mathrm{C}$. These temperatures are consistent with the mean temperatures observed in stratiform clouds and

20 precipitated ice; further evidencing the possibility of HOIC taking the form of dendritic ice crystals. Although temperature is known to be the primary factor in determining the habit of ice crystals, supersaturation also plays an important role.

\subsection{The Role of Relative Humidity in HOIC}

25 On average, HOIC occurs in both stratiform clouds and precipitation at higher RHs than ROIC. This suggests that larger ice crystals are being formed given the relationship between RH and ice supersaturation (Bailey, M. and Hallett, 2004; 2009). A larger ice crystal within the plate regime would 
Atmos. Chem. Phys. Discuss., doi:10.5194/acp-2016-1134, 2017

have a larger surface area and would be more likely to orientate preferentially (Bréon and Dubrulle, 2004).

The lack of a difference in RH between HOIC and ROIC in cirrus however suggests $\mathrm{RH}$ is not

5 important in the formation of HOIC in cirrus clouds despite the influence it could have on ice crystal size. Differences in RH between ROIC and HOIC in stratiform clouds and precipitated ice would suggest RH is important in determining the size of crystals, and that larger crystals are more likely to orientate preferentially as suggested by Bréon and Dubrulle, (2004).

\section{4.4 Horizontal Wind Speed Dependence of HOIC}

HOIC in stratiform clouds, cirrus clouds and precipitation all occur at higher wind speeds than ROIC (and liquid in stratiform clouds). The horizontal wind speeds presented here agree with the findings of Noel and Chepfer (2010), as HOIC occur on average at horizontal wind speeds below $30 \mathrm{~ms}^{-1}$. All average wind speeds of HOIC being lower than $20 \mathrm{~ms}^{-1}$ is consistent with the observations of Noel et al

15 (2006), who found plate like ice crystals are most likely to occur at wind speeds below $20 \mathrm{~ms}^{-1}$.

What seems surprising is that HOIC occur on average at a higher horizontal wind speeds than ROIC with the largest difference in mean wind speed between HOIC and ROIC can be seen in cirrus clouds. Thus, the findings of this study suggest that increased horizontal wind speed encourages orientation.

20 This needs to be examined further in relation to vertical fall speeds. The role of horizontal and vertical dynamic's will be investigated further with co-incident Doppler radar and lidar measurements in a future study.

\subsection{The Influence of Height on HOIC}

25 The heights at which HOIC occur on average are below that of ROIC. This could be related to the role of atmospheric pressure in the formation of ice crystals (Bailey and Hallett, 2009). Differences in the atmospheric pressure could be responsible for changes differences within the plate regime of ice crystals, which has been defined by the mean temperatures of HOIC. 
HOIC in precipitation and stratiform clouds were found to occur at similar mean temperatures and RHs. Although the conditions are similar, there is a mean difference of $200 \mathrm{~m}$ in the heights of precipitated HOIC and HOIC in stratiform clouds, precipitated HOIC occurring lower in the atmosphere. The equal

5 temperatures of both precipitated HOIC and HOIC in stratiform clouds would suggest that both are of the same ice crystals habit. This consistency in the temperatures of HOIC between stratiform clouds and precipitation, and their similar RHs, may suggest ice crystals being formed in stratiform clouds and precipitated from it maintaining its habit and size.

\section{4.6 Seasonality in HOIC}

Noel and Chepfer (2010) found no seasonal variation of HOIC on a global scale. The initial findings of CAPABL's observations do not concur with this. HOIC can be seen to vary in, the number of detections peaking in spring and autumn months of April and October. We suggest that peaks in the number of detections could be related to the positive feedback mechanism proposed by Sassen et al. (2003)

15 between solar heating and cirrus clouds at mid-latitudes but this will take more observations to examine fully. Yet, the feedback mechanism suggested for cirrus clouds may not be applicable to the stratiform clouds containing HOIC we observe at Summit because of their higher optical depth. As a result of this, the direct effect of solar radiation on the formation of HOIC towards the bottom of stratiform clouds or precipitated HOIC could be limited. CAPABL's observations could also be missing the presence of

20 HOIC at the top of these clouds for the same reason, thus comparison of satellite observations with ground observations is warranted. Even so, the data currently being collected suggests that the large number of detections HOIC in April could be due to the Sassen et al. (2003) feedback mechanism.

The physical process at the centre of the positive feedback mechanism proposed by Sassen et al. (2003)

25 is solar heating. A similar mechanism could be occurring with occurrences of HOIC at Summit on an annual basis. From Figures 5, with the exception of January, summer, spring and autumn months have higher numbers of detection. The seasonal variability in the abundance sunlight largely corresponds with this. The number of days containing HOIC is typically higher during the months during which 
Atmos. Chem. Phys. Discuss., doi:10.5194/acp-2016-1134, 2017

sunlight is available. Should this relationship between solar heating and the occurrence of HOIC be true, it only emphasizes the importance of temperature in the formation of HOIC.

\subsection{Sources of Error}

5 The major short coming of this study is the relatively short time scale of the study. We do not make any claims that this work is a climatology as it is a first look at the behaviour of HOIC over Summit. Analysis of temporal variability over a longer time period will be needed to validate the findings of this study before robust seasonal and monthly tendencies can be identified.

10 The innate sampling error due to the fact that CAPABL measures clouds from below is another issue that should be kept in mind when examining these results and comparing them to results from satellite observations. While satellite studies will be biased towards observations of cirrus and cloud tops, CAPABL is most likely biased to observing HOIC in falling/precipitating ice or in the bottom of stratiform clouds. This, the prevalence of HOIC to occur in stratiform clouds over Summit, as shown in

15 Figure 6, may be due solely to the fact that CAPABL cannot see above such clouds which are present a majority of the time at Summit. A comparison of HOIC climatologies derived from both satellite observations and ground-based will be needed to understand the difference between sampling biases and geophysical differences.

20 The criteria set and which represent the assumptions used in the masking process are also a source of error. Values of depolarisation, and indeed diattenuation, although consistent with other similar studies could still be erroneous based on measurement errors and multiple scattering. Stillwell et al. (2016) outlines that depolarisation ratios can be as high as 0.3 from multiple scattering identification of liquid and instrument effects, much higher than the 0.11 used in this study. Measuring the horizontal

25 orientation of ice crystal through diattenuation is a new concept. To the authors knowledge, the only other values of diattenuation quoted in literature for the detection limit of HOIC are found in Neely et al. (2013) and Stillwell et al. (2016) and, both using a value of 0.05. In comparison Hayman et al. (2012), using a similar measurement technique to that implemented in CAPABL made observations of 
Atmos. Chem. Phys. Discuss., doi:10.5194/acp-2016-1134, 2017

HOIC in cirrus in Boulder, $\mathrm{CO}$ that exhibited a diattenuation value of $\sim 0.07$ and greater but did not specify a detection limit. In order for a direct comparison to be made, the square root of the value set here (0.005) must be taken, giving a value of 0.07 . This value, for crystals of equal scattering efficiency, requires a larger fraction of the population of ice crystals to be horizontally oriented for HOIC (Neely et

5 al. 2013). In comparison to the value of Stillwell et al. (2016) and Neely et al. (2013), the value used in this study is more stringent. Whether this criterion is too stringent is difficult to tell given the few studies using diattenuation to detect HOIC. Only the continued research into HOIC using observations with CAPABL is required in order to put the value of diattenuation specified here into context. Related to this is the amount of error considered in the criteria.

Finally, there is a significant representivity error is associated with the gridding and linear interpolation of radiosonde observations. In this work, the observations have only been used to characterise the bulk properties of the atmosphere when HOIC have been observed because the coarse temporal resolution of observations, in comparison to the speed of the processes associated with HOIC, may be dampening

15 signals of important process in the thermodynamic and turbulent conditions in which HOIC occur. For a more detailed examination of the dynamics and thermodynamics a higher resolution dataset of winds and atmospheric state will be needed to compare with CAPABL's observations.

The assumptions made regarding the statistical analysis could introduce error to the study. Should

20 another statistical distribution better fit the data presented in this study, this could alter the conclusions drawn here. Assuming all data is distributed in the same way, perhaps a log-normal distribution better captures the distribution of data within the histograms of Figure 11.

\section{Summary}

25 Here occurrences of HOIC in the clouds above Summit, Greenland were explored between July 2015 and May 2016. The analysis undertaken by this study aims to further the knowledge base of Arctic clouds by determining the conditions that allow for HOIC to occur. From surveying the existing literature, it is of high importance that the effect of cloud microphysical properties on Arctic CRF is 
Atmos. Chem. Phys. Discuss., doi:10.5194/acp-2016-1134, 2017

understood. The current representation of Arctic CRF in climate models is poor. Identifying the conditions that allow for specific microphysical properties to occur, such as HOIC, is the first step in identifying the impact they have on CRF. Knowing the impact HOIC have on CRF will eventually lead to their accurate representation in climate simulations. This study has shown that between July 2015 and

5 May 2016, HOIC were most common in stratiform clouds, occurring on 48 days. HOIC were in present in precipitation on 33 days and were least common in cirrus clouds, occurring on 14 days. On average, HOIC in stratiform occurred at $0.85 \mathrm{~km}$ AGL, lower in the atmosphere than ice assumed to be randomly oriented but higher than liquid. HOIC also occurred lower than ROIC in cirrus and precipitated ice at $2.13 \mathrm{~km}$ AGL and $0.65 \mathrm{~km}$ AGL respectively.

From analysis of the thermodynamic and turbulent conditions allowing for HOIC consistent patterns emerged in temperature, $\mathrm{RH}$ and wind speed. The mean temperatures of $\mathrm{HOIC}$, for all cases were higher than those for ROIC and all were within the plate ice crystal habit regime of Bailey and Hallett (2009). $\mathrm{HOIC}$ were found to occur in both stratiform clouds and precipitation at a mean temperature of $-20^{\circ} \mathrm{C}$ 15 and at $-33^{\circ} \mathrm{C}$ in cirrus. The temperature of HOIC in stratiform clouds was also lower than that of liquid. The mean RH of HOIC was higher than that of ROIC in both stratiform clouds and precipitation but no difference in RH was found in cirrus clouds. On average, HOIC occurred at higher wind speeds than ROIC (and liquid in stratiform clouds). All wind speeds were within the range identified for HOIC by Noel and Chepfer (2010), including those of ROIC. The higher wind speeds that allow for HOIC to

20 occur also correspond to the wind speeds allowing for ice crystals within the plate regime to form.

Analysis over the whole study period found that HOIC were detected by CAPABL on average in 2.9\% of the time and are most likely representative of a much larger population of HOIC in clouds (Neely et al. 2013). Monthly variations in the frequency of occurrence found HOIC to most frequent in January,

25 December. The patterns found in the frequency of occurrence of HOIC do not correlate well with the monthly numbers of detections of HOIC or the number days per month containing HOIC. The number of detections peaked in April and October and were at their lowest in November, December and February. Stratiform clouds was seen to contain HOIC on at least 2 days per month, with the exception 
Atmos. Chem. Phys. Discuss., doi:10.5194/acp-2016-1134, 2017

Manuscript under review for journal Atmos. Chem. Phys.

Discussion started: 16 March 2017

(c) Author(s) 2017. CC-BY 3.0 License.

of February when no days contained HOIC bearing stratiform. The number of days containing stratiform peaked in May and July with 7 and 9 days per month respectively. HOIC were mainly present in February in cirrus clouds. Outside of February, HOIC occurred on 8 days in cirrus clouds. These days were evenly split between March and April. HOIC in precipitation was present on 0 days of February

5 and December and occurred most often in April, May and September.

The observations presented here provide the first documentation of seasonal variations in the presence of HOIC at Summit, Greenland and are the first steps in the development of a climatology. This study has shed light on when where and why HOIC are occurring but is subject to limitations; these

10 limitations however can be overcome. Future work should further investigate the role of turbulence in the formation of HOIC and utilize the MMCR available at Summit. This will be useful in conforming the role of turbulence in the formation HOIC which is debated. Another useful area for future research is the sensitivity of HOIC to wind direction as air mass properties which are already known to affect the SEB. Sampling of temperature and horizontal wind at a higher temporal resolution would also be

15 beneficial for future research. Analysis of temporal variabilities in future work should extend and continue on from the study period used here. A crucial area for future studies to explore is the radiative properties of HOIC, especially their long wave effect.

\section{Acknowledgments}

This material is based upon work supported by the National Science Foundation Graduate Research

20 Fellowship Program under Grant No. DGE 1144083, National Science Foundation Grants PLR1303864, PLR-1303879, PLR-1314156, and ATM-0454999. Ryan Neely is funded by the National Centre for Atmospheric Science. All the authors would like to especially thank the staff and science technicians at Summit Station as well as the entire team at Polar Field Services for their support and dedication to help maintain the instrumentation and collect the data presented in this work. 
Atmos. Chem. Phys. Discuss., doi:10.5194/acp-2016-1134, 2017

Manuscript under review for journal Atmos. Chem. Phys.

Discussion started: 16 March 2017

(c) Author(s) 2017. CC-BY 3.0 License.

\section{References}

Bailey, M. and Hallett, J.: Growth rates and habits of ice crystals between-20 and-70 C, J. Atmos. Sci., doi:10.1175/1520-0469(2004)061<0514:GRAHOI>2.0.CO;2, 2004.

5 Bailey, M. P. and Hallett, J.: A Comprehensive Habit Diagram for Atmospheric Ice Crystals:

Confirmation from the Laboratory, AIRS II, and Other Field Studies, Journal of Atmospheric Sciences, 66(9), 2888-2899, doi:10.1175/2009JAS2883.1, 2009.

Bennartz, R., Shupe, M. D., Turner, D. D., Walden, V. P., Steffen, K., Cox, C. J., Kulie, M. S., Miller,

10 N. B. and Pettersen, C.: July 2012 Greenland melt extent enhanced by low-level liquid clouds, Nature, 496(7443), 83-86, doi:10.1038/nature12002, 2013.

Bréon, F.-M. and Dubrulle, B.: Horizontally Oriented Plates in Clouds, Journal of Atmospheric Sciences, 61(23), 2888-2898, doi:10.1175/JAS-3309.1, 2004.

15

Cawkwell, F. and Bamber, J. L.: The impact of cloud cover on the net radiation budget of the Greenland ice sheet, Annals of Glaciology, 34(1), 141-149, doi:10.3189/172756402781817789, 2002.

Chen, T., Rossow, W. B. and Zhang, Y.: Radiative effects of cloud-type variations, Journal of Climate, 13(1), 264-286, doi:10.1175/1520-0442(2000)013<0264:REOCTV>2.0.CO;2, 2000.

Chepfer, H., Brogniez, G., Goloub, P., Bréon, F. M. and Flamant, P. H.: Observations of horizontally oriented ice crystals in cirrus clouds with POLDER-1/ADEOS-1, Journal of Quantitative Spectroscopy and Radiative Transfer, 63(2-6), 521-543, doi:10.1016/S0022-4073(99)00036-9, 1999.

Corti, T. and Peter, T.: A simple model for cloud radiative forcing, Atmospheric Chemistry and Physics, 2009. 
Atmos. Chem. Phys. Discuss., doi:10.5194/acp-2016-1134, 2017

Manuscript under review for journal Atmos. Chem. Phys.

Discussion started: 16 March 2017

(c) Author(s) 2017. CC-BY 3.0 License.

Cox, C. J., Turner, D. D., Rowe, P. M., Shupe, M. D. and Walden, V. P.: Cloud Microphysical

Properties Retrieved from Downwelling Infrared Radiance Measurements Made at Eureka, Nunavut, Canada (2006-09), J. Appl. Meteor. Climatol., 53(3), 772-791, doi:10.1175/JAMC-D-13-0113.1, 2014.

5 Curry, J. A. and Ebert, E. E.: Annual cycle of radiation fluxes over the Arctic Ocean: Sensitivity to cloud optical properties, Journal of Climate, 5(11), 1267-1280, doi:10.1175/15200442(1992)005<1267:ACORFO >2.0.CO;2, 1992.

la Pena, de, S., Howat, I. M. and Nienow, P. W.: Changes in the firn structure of the western Greenland

10 Ice Sheet caused by recent warming, The Cryosphere, doi:10.5194/tc-9-1203-2015, 2015.

Hayman, M. and Thayer, J. P.: General description of polarization in lidar using Stokes vectors and polar decomposition of Mueller matrices, J. Opt. Soc. Am. A, JOSAA, 29(4), 400-409, doi:10.1364/JOSAA.29.000400, 2012a.

15

Hayman, M., Spuler, S., Morley, B. and VanAndel, J.: Polarization lidar operation for measuring backscatter phase matrices of oriented scatterers, Optics Express, 20(28), 29553-29567, doi:10.1364/OE.20.029553, 2012b.

20 Hess, M. and Wiegner, M.: COP: a data library of optical properties of hexagonal ice crystals, Applied Optics, 1994.

Hirakata, M., Okamoto, H., Hagihara, Y., Hayasaka, T. and Oki, R.: Comparison of Global and Seasonal Characteristics of Cloud Phase and Horizontal Ice Plates Derived from CALIPSO with

25 MODIS and ECMWF, Journal of Atmospheric and Oceanic Technology, 31(10), 2114-2130, doi:10.1175/JTECH-D-13-00245.1, 2014. 
Atmos. Chem. Phys. Discuss., doi:10.5194/acp-2016-1134, 2017

Manuscript under review for journal Atmos. Chem. Phys.

Discussion started: 16 March 2017

(c) Author(s) 2017. CC-BY 3.0 License.

Intrieri, J., Shupe, M. and Uttal, T.: An annual cycle of Arctic cloud characteristics observed by radar and lidar at SHEBA, J. Geophys. Res, 107(C10), 8030, doi:10.1029/2000jc000423, 2002.

Kay, J. E. and L'Ecuyer, T.: Observational constraints on Arctic Ocean clouds and radiative fluxes

5 during the early 21st century, Journal of Geophysical Research-Atmospheres, 118(13), 7219-7236, doi:10.1002/jgrd.50489, 2013.

Kaul, B., Samokhvalov, I. and Volkov, S.: Investigating particle orientation in cirrus clouds by measuring backscattering phase matrices with lidar, Applied Optics, 43(36), 6620-6628,

10 doi:10.1364/ao.43.006620, 2004.

Kjeldsen, K. K., Korsgaard, N. J., Bjørk, A. A., Khan, S. A., Box, J. E., Funder, S., Larsen, N. K., Bamber, J. L., Colgan, W., van den Broeke, M., Siggaard-Andersen, M.-L., Nuth, C., Schomacker, A., Andresen, C. S., Willerslev, E. and Kjær, K. H.: Spatial and temporal distribution of mass loss from the

15 Greenland Ice Sheet since AD 1900, Nature, 528(7582), 396-400, doi:10.1038/nature16183, 2015.

Klett, J. D.: Orientation model for particles in turbulence, J. Atmos. Sci., doi:10.1175/15200469(1995)052<2276:OMFPIT>2.0.CO;2, 1995.

20 Miller, N. B., Shupe, M. D., Cox, C. J., P Walden, Von, Steffen, K., P Walden, Von, Turner, D. D. and Steffen, K.: Cloud Radiative Forcing at Summit, Greenland, http://dx.doi.org/10.1175/JCLI-D-150076.1, 28(15), 6267-6280, doi:10.1175/JCLI-D-15-0076.1, 2015.

Morrison, H., de Boer, G., Feingold, G., Harrington, J., Shupe, M. D. and Sulia, K.: Resilience of 25 persistent Arctic mixed-phase clouds, Nature Geoscience, 5(1), 11-17, doi:10.1038/ngeo1332, 2012. 
Atmos. Chem. Phys. Discuss., doi:10.5194/acp-2016-1134, 2017

Manuscript under review for journal Atmos. Chem. Phys.

Discussion started: 16 March 2017

(c) Author(s) 2017. CC-BY 3.0 License.

Noel, V., Chepfer, H. and Haeffelin, M.: Classification of ice crystal shapes in midlatitude ice clouds from three years of lidar observations over the SIRTA observatory, Journal of the Atmospheric Sciences, doi:10.1175/JAS3767.1, 2006.

5 Noel, V. and Chepfer, H.: A global view of horizontally oriented crystals in ice clouds from CloudAerosol Lidar and Infrared Pathfinder Satellite Observation (CALIPSO), J. Geophys. Res, 115(D4), D00H23-13, doi:10.1029/2009JD012365, 2010.

Neely, R. R., III, Hayman, M., Stillwell, R., Thayer, J. P., Hardesty, R. M., O'Neill, M., Shupe, M. D.

10 and Alvarez, C.: Polarization Lidar at Summit, Greenland, for the Detection of Cloud Phase and Particle Orientation, Journal of Atmospheric and Oceanic Technology, 30(8), 1635-1655, doi:10.1175/JTECHD-12-00101.1, 2013.

Neff, W., Compo, G. P., Ralph, F. M. and Shupe, M. D.: Continental heat anomalies and the extreme melting of the Greenland ice surface in 2012 and 1889,, 1-17, doi:10.1002/(ISSN)2169-8996, 2014.

Noel, V. and Chepfer, H.: Study of ice crystal orientation in cirrus clouds based on satellite polarized radiance measurements, J. Atmos. Sci., doi:10.1175/1520-0469(2004)061<2073:SOICOI>2.0.CO;2, 2004.

20 Noel, V. and Chepfer, H.: A global view of horizontally oriented crystals in ice clouds from CloudAerosol Lidar and Infrared Pathfinder Satellite Observation (CALIPSO), J. Geophys. Res, 115(D4), D00H23-13, doi:10.1029/2009JD012365, 2010.

Platt, C.: Lidar backscatter from horizontal ice crystal plates, Journal of Applied Meteorology, 25 doi:10.1175/1520-0450(1978)017<0482:LBFHIC>2.0.CO;2, 1978.

Petty, G.W., 2004. A first course in atmospheric radiation, Sundog Publishing, Madison, Wisconsin, 2004. 
Atmos. Chem. Phys. Discuss., doi:10.5194/acp-2016-1134, 2017

Manuscript under review for journal Atmos. Chem. Phys.

Discussion started: 16 March 2017

(c) Author(s) 2017. CC-BY 3.0 License.

Ramanathan, V., Cess, R. D., Harrison, E. F., Minnis, P., Barkstrom, B. R., Ahmad, E. and Hartmann, D.: Cloud-radiative forcing and climate: Results from the Earth Radiation Budget Experiment, Science, 243(4887), 57-63, doi:10.1126/science.243.4887.57, 1989.

5

Sassen, K., Liou, K.-N., Takano, Y. and Khvorostyanov, V. I.: Diurnal effects in the composition of cirrus clouds, Geophys. Res. Lett, 30(10), n/a-n/a, doi:10.1029/2003GL017034, 2003.

Shupe, M. and Intrieri, J.: Cloud Radiative Forcing of the Arctic Surface: The Influence of Cloud

10 Properties, Surface Albedo, and Solar Zenith Angle, Journal of Climate, 17, 616-628, doi:10.1175/1520-0442(2004)017<0616:crfota>2.0.co;2, 2004.

Shupe, M., Uttal, T. and Matrosov, S. : Arctic cloud microphysics retrievals from surface-based remote sensors at SHEBA, Journal of Applied Meteorology, 44(10), 1544-1562, doi:10.1175/jam2297.1, 2005. 15

Shupe, M. D., Turner, D. D., Walden, V. P., Bennartz, R., Cadeddu, M. P., Castellani, B. B., Cox, C. J., Hudak, D. R., Kulie, M. S., Miller, N. B., Neely, R. R., III, Neff, W. D. and Rowe, P. M.: High and Dry: New Observations of Tropospheric and Cloud Properties above the Greenland Ice Sheet, Bulletin of the American Meteorological Society, 94(2), 169-186, doi:10.1175/BAMS-D-11-00249.1, 2013. 20

Stillwell, R. A., Neely, R. R., III, Thayer, J. P., Shupe, M. D. and O amp apos Neill, M.: Low-Level, Liquid-Only and Mixed-Phase Cloud Identification by Polarimetric Lidar, Atmos. Meas. Tech. Discuss., 1-33, doi:10.5194/amt-2016-303, 2016.

25 Westbrook, C. D., Illingworth, A. J., O'Connor, E. J. and Hogan, R. J.: Doppler lidar measurements of oriented planar ice crystals falling from supercooled and glaciated layer clouds, Quarterly Journal of the Royal Meteorological Society, 136(646), 260-276, doi:10.1002/qj.528, 2009. 
Atmos. Chem. Phys. Discuss., doi:10.5194/acp-2016-1134, 2017

Manuscript under review for journal Atmos. Chem. Phys.

Discussion started: 16 March 2017

(c) Author(s) 2017. CC-BY 3.0 License.

Sun, Z. and Shine, K. P.: Studies of the radiative properties of ice and mixed-phase clouds, Quarterly Journal of the Royal Meteorological Society, 120(515), 111-137, doi:10.1002/qj.49712051508, 1994.

Takano, Y. and Liou, K. N.: Solar radiative transfer in cirrus clouds. Part I: Single-scattering and optical

5 properties of hexagonal ice crystals, J. Atmos. Sci., 46(1), 3-19, doi:10.1175/1520-

0469(1989)046<0003:SRTICC>2.0.CO;2, 1989.

Takano, Y. and Liou, K. N.: Transfer of polarized infrared radiation in optically anisotropic media: application to horizontally oriented ice crystals, J. Opt. Soc. Am. A, JOSAA, 10(6), 1243,

10 doi:10.1364/josaa.10.001243, 1993.

Thomas, L. and Cartwright, J.: Lidar observations of the horizontal orientation of ice crystals in cirrus clouds, Tellus B, 42(2), 211-216, doi:10.1034/j.1600-0889.1990.00001.x-i1, 1990.

15 Tricker, R. A. R.: Introduction to meteorological optics, Introduction to meteorological optics, Mills and Boon, London, UK, 1971.

van den Broeke, M., Bamber, J., Ettema, J., Rignot, E., Schrama, E., van de Berg, W. J., van Meijgaard, E., Velicogna, I. and Wouters, B.: Partitioning Recent Greenland Mass Loss, Science, 326(5955), 984

20 986, doi:10.1126/science.1178176, 2009.

Van Tricht, K., Lhermitte, S. and Lenaerts, J.: Clouds enhance Greenland ice sheet meltwater runoff, Nat Comms, 7, 10266, doi:10.1038/ncomms10266, 2016.

25 Westbrook, C. D., Illingworth, A. J., O'Connor, E. J. and Hogan, R. J.: Doppler lidar measurements of oriented planar ice crystals falling from supercooled and glaciated layer clouds, Quarterly Journal of the Royal Meteorological Society, 136(646), 260-276, doi:10.1002/qj.528, 2009. 
Atmos. Chem. Phys. Discuss., doi:10.5194/acp-2016-1134, 2017

Manuscript under review for journal Atmos. Chem. Phys.

Discussion started: 16 March 2017

(c) Author(s) 2017. CC-BY 3.0 License.

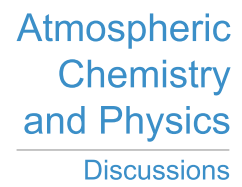

(c) (i)

Westbrook, C. D.: Origin of the Parry arc, Quarterly Journal of the Royal Meteorological Society, 137(655), 538-543, doi:10.1002/qj.761, 2011.

Whipple, F. J. W.: How are mock suns produced? Quarterly Journal of the Royal Meteorological

5 Society, 66(286), 275-280, doi:10.1002/qj.49706628603, 1940.

Zhou, C., Yang, P., Dessler, A. E. and Liang, F.: Statistical Properties of Horizontally Oriented Plates in Optically Thick Clouds From Satellite Observations, IEEE Geosci. Remote Sensing Lett., 10(5), 986990, doi:10.1109/LGRS.2012.2227451, 2013.

10 
Atmos. Chem. Phys. Discuss., doi:10.5194/acp-2016-1134, 2017

Manuscript under review for journal Atmos. Chem. Phys.

Discussion started: 16 March 2017

(c) Author(s) 2017. CC-BY 3.0 License.
Atmospheric

Chemistry

and Physics

Discussions
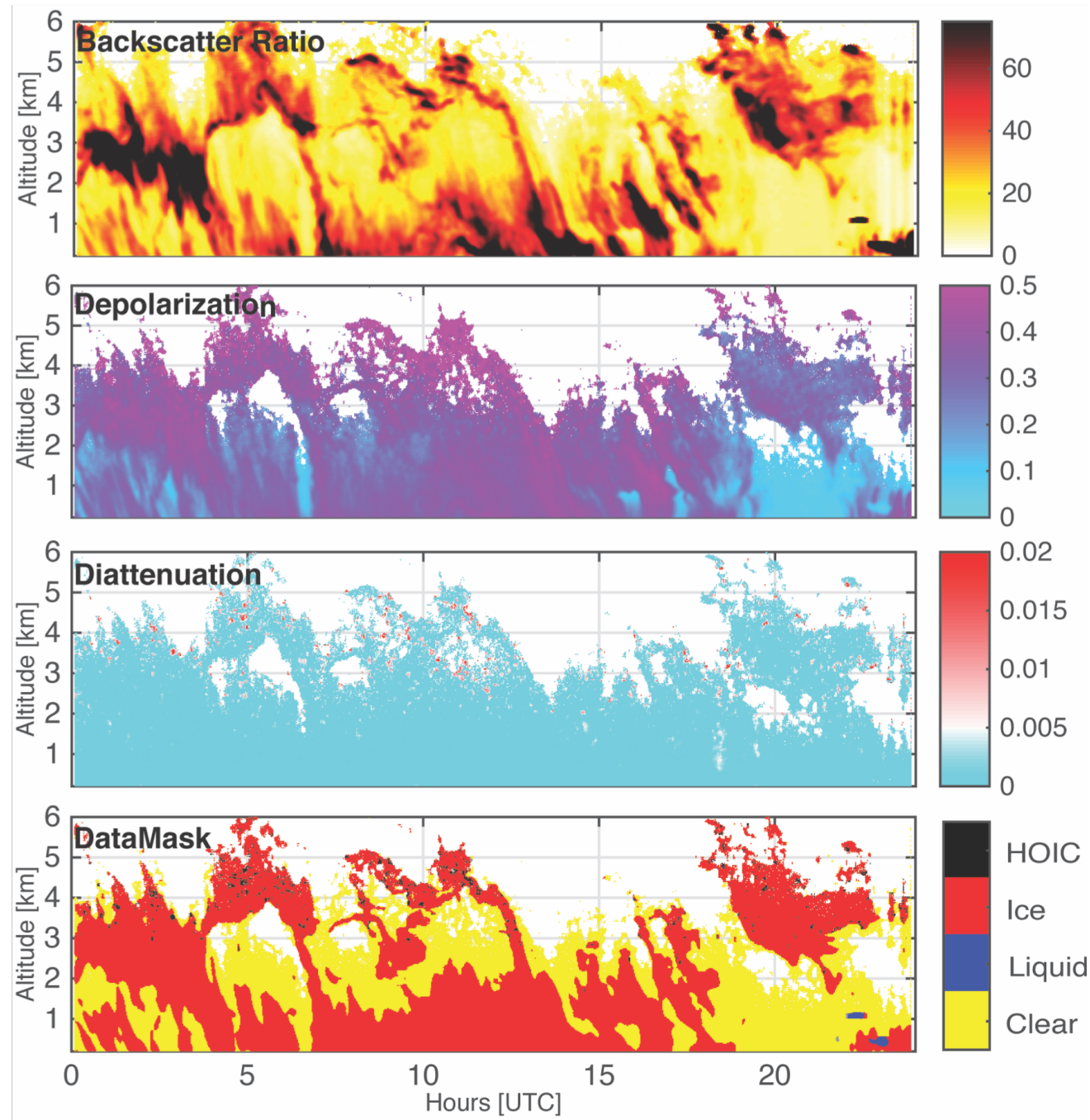

Figure 1. Example CAPABL observations on 20 February 2016 from 00:00 to 24:00 UTC of backscatter ratio, depolarization ratio, diattenuation and the masking process as described in this section. Occurrences of HOIC are outlined in black and are masked in green. 
Atmos. Chem. Phys. Discuss., doi:10.5194/acp-2016-1134, 2017

Manuscript under review for journal Atmos. Chem. Phys.

Discussion started: 16 March 2017

(c) Author(s) 2017. CC-BY 3.0 License.
Atmospheric

Chemistry

and Physics

Discussions
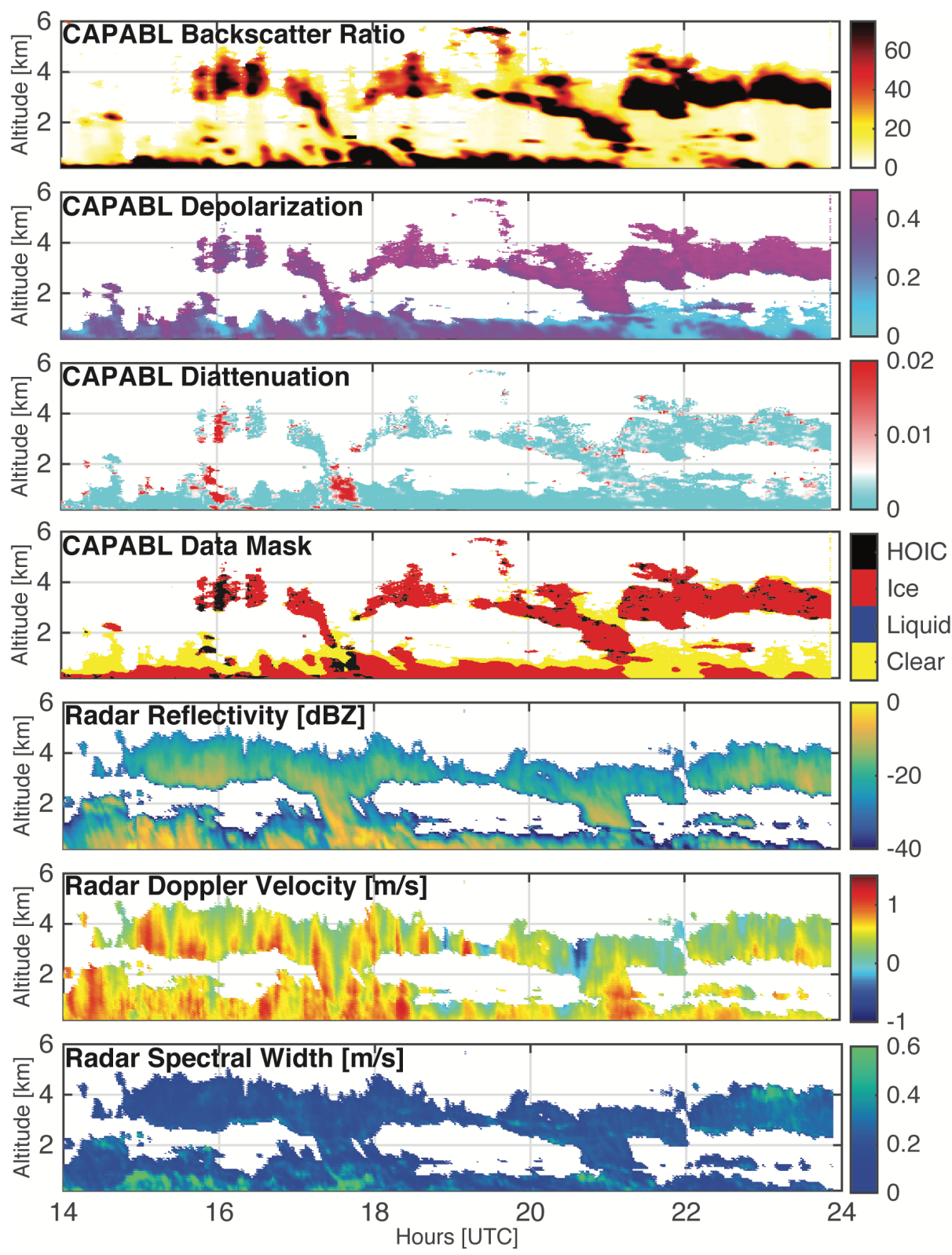

Figure 2 Observations made on from 14:00 to 24:00 UTC on April 22, 2016 from CAPABL and NOAA MMCR. Positive values in the Doppler velcoty indicate a downward direction. The white coloring in the diattenuation plot denotes the 0.005 threshhold for HOIC. HOIC occurrs at 16:00 in cirrus at $4 \mathrm{~km}$, in stratiform cloud at $1.5 \mathrm{~km}$ and in precipitating ice near the surface, at 18:00 in 5 precipitating/falling ice and at 20:00 onwards in cirrus cloud at $4 \mathrm{~km}$. 
Atmos. Chem. Phys. Discuss., doi:10.5194/acp-2016-1134, 2017

Manuscript under review for journal Atmos. Chem. Phys.

Discussion started: 16 March 2017

(c) Author(s) 2017. CC-BY 3.0 License.

\section{(c) (i)}
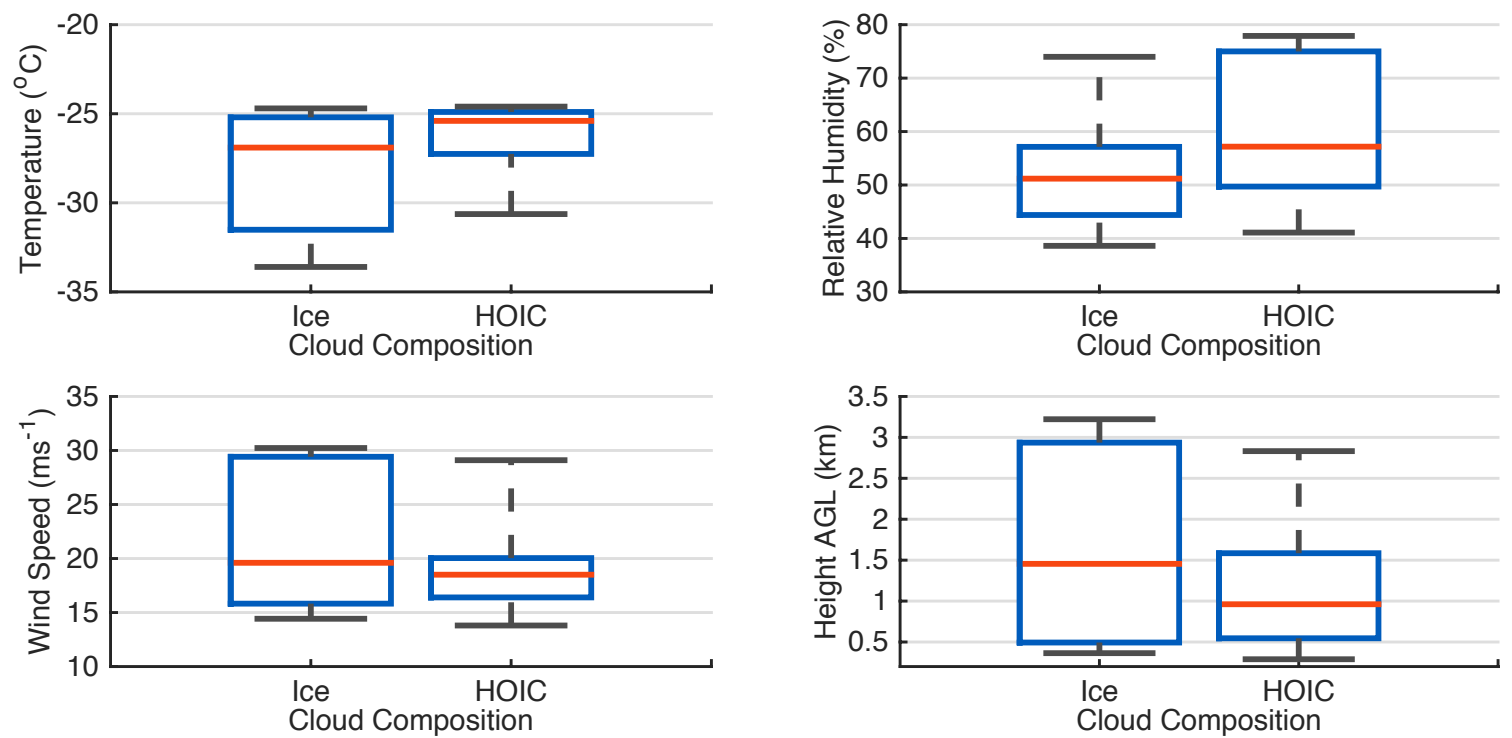

Figure 3 Comparison of condition in which ROIC and HOIC occurred in Figure 2 using CAPABL's masking from Figure 2 and interpolated radiosonde profiles launched $12 Z$ on April 22, 2016 and $00 Z$ on April 23, 2016. Boxes include the $25^{\text {th }}$ to $75^{\text {th }}$

5 percentiles and whiskers extend to the $10^{\text {th }}$ and $90^{\text {th }}$ percentiles. 
Atmos. Chem. Phys. Discuss., doi:10.5194/acp-2016-1134, 2017

Manuscript under review for journal Atmos. Chem. Phys.

Discussion started: 16 March 2017

(C) Author(s) 2017. CC-BY 3.0 License.

(c) (1)
Atmospheric

Chemistry

and Physics

Discussions

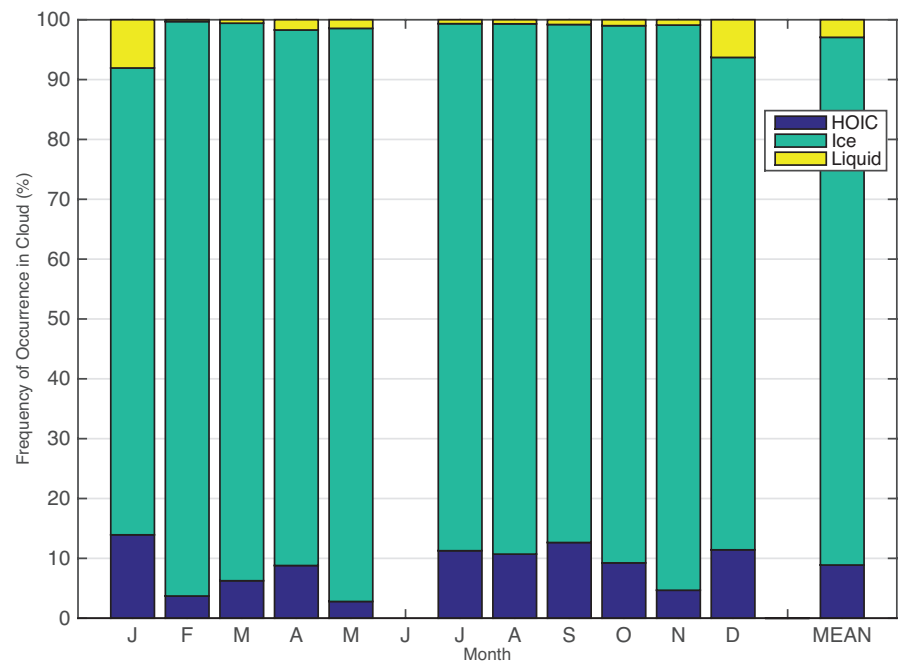

Figure 4 Monthly frequencies of occurrence of HOIC in comparison to Ice (assumed to be randomly oriented) and Liquid cloud. 
Atmos. Chem. Phys. Discuss., doi:10.5194/acp-2016-1134, 2017

Manuscript under review for journal Atmos. Chem. Phys.

Discussion started: 16 March 2017

(c) Author(s) 2017. CC-BY 3.0 License.

\section{(c) (1)}

\section{Atmospheric \\ Chemistry \\ and Physics \\ Discussions}

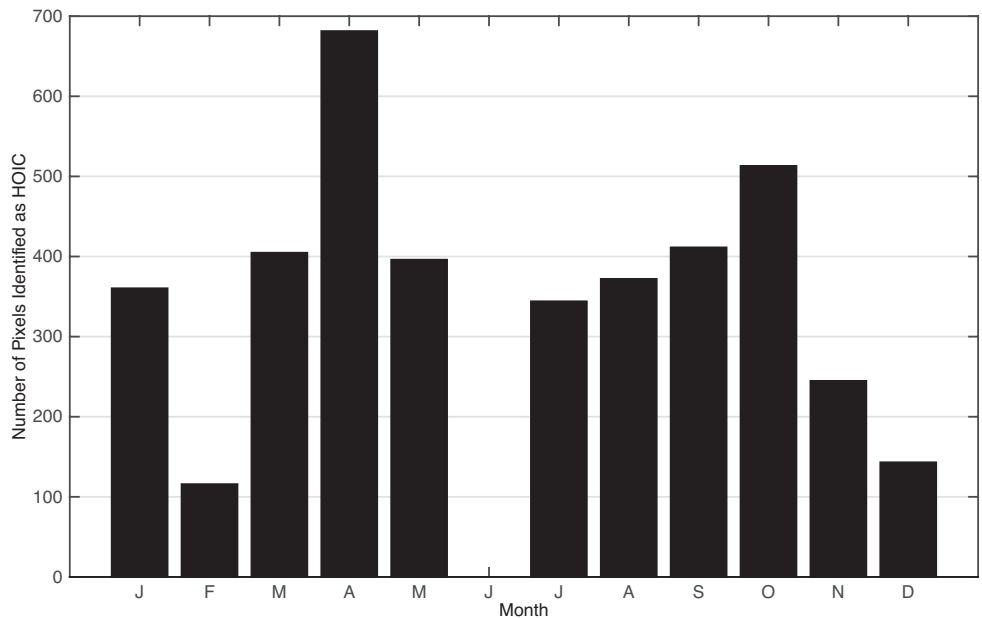

Figure 5 Total monthly pixels detected to contain HOIC resulting from the masking process. 
Atmos. Chem. Phys. Discuss., doi:10.5194/acp-2016-1134, 2017

Manuscript under review for journal Atmos. Chem. Phys.

Discussion started: 16 March 2017

(c) Author(s) 2017. CC-BY 3.0 License.

\section{(c) (i)}

Atmospheric

Chemistry

and Physics

Discussions

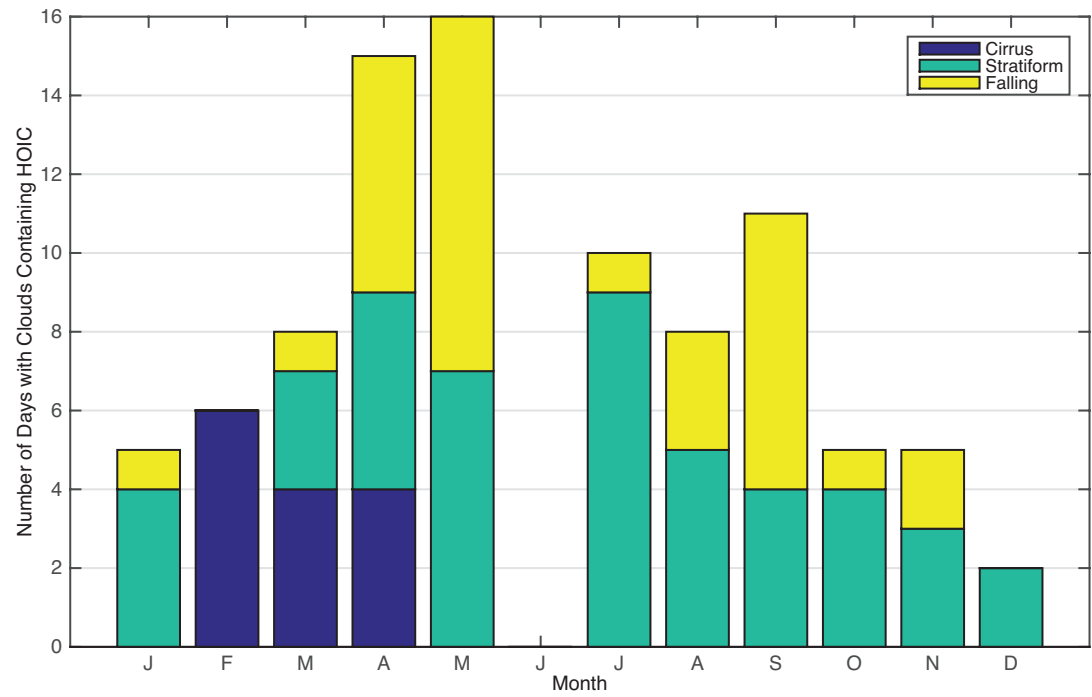

Figure 6 Monthly totals of days containing HOIC. Monthly totals are split into the 3 categories of cirrus, stratiform of falling/precipitated HOIC. 
Atmos. Chem. Phys. Discuss., doi:10.5194/acp-2016-1134, 2017

Manuscript under review for journal Atmos. Chem. Phys.

Discussion started: 16 March 2017

(c) Author(s) 2017. CC-BY 3.0 License.

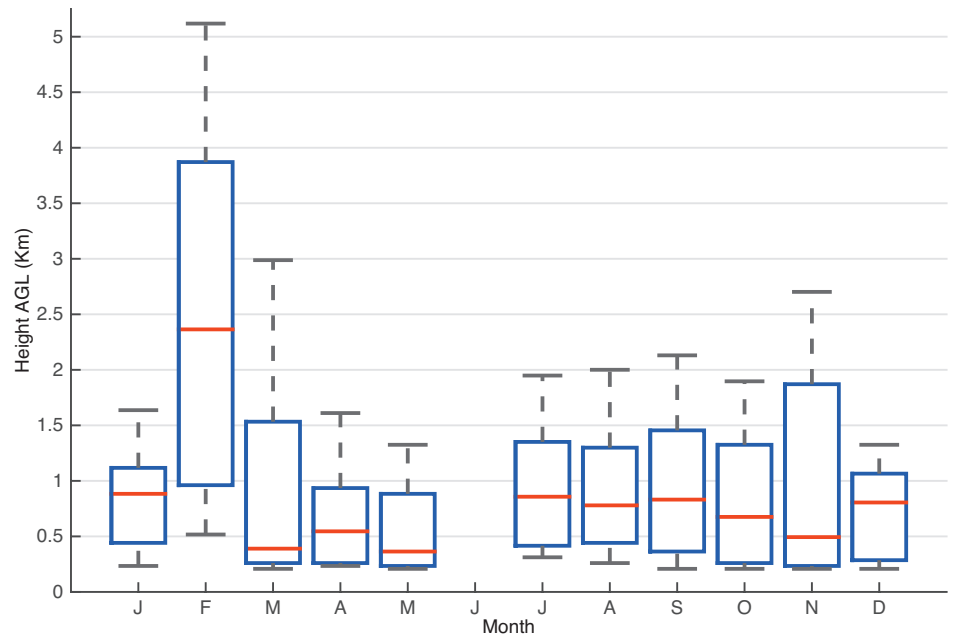

Figure 7. Monthly variations in the heights at which HOIC were observed. Boxes include the $25^{\text {th }}$ to $75^{\text {th }}$ percentiles and whiskers extend to the $10^{\text {th }}$ and $90^{\text {th }}$ percentiles. 
Atmos. Chem. Phys. Discuss., doi:10.5194/acp-2016-1134, 2017

Manuscript under review for journal Atmos. Chem. Phys.

Discussion started: 16 March 2017

(c) Author(s) 2017. CC-BY 3.0 License.
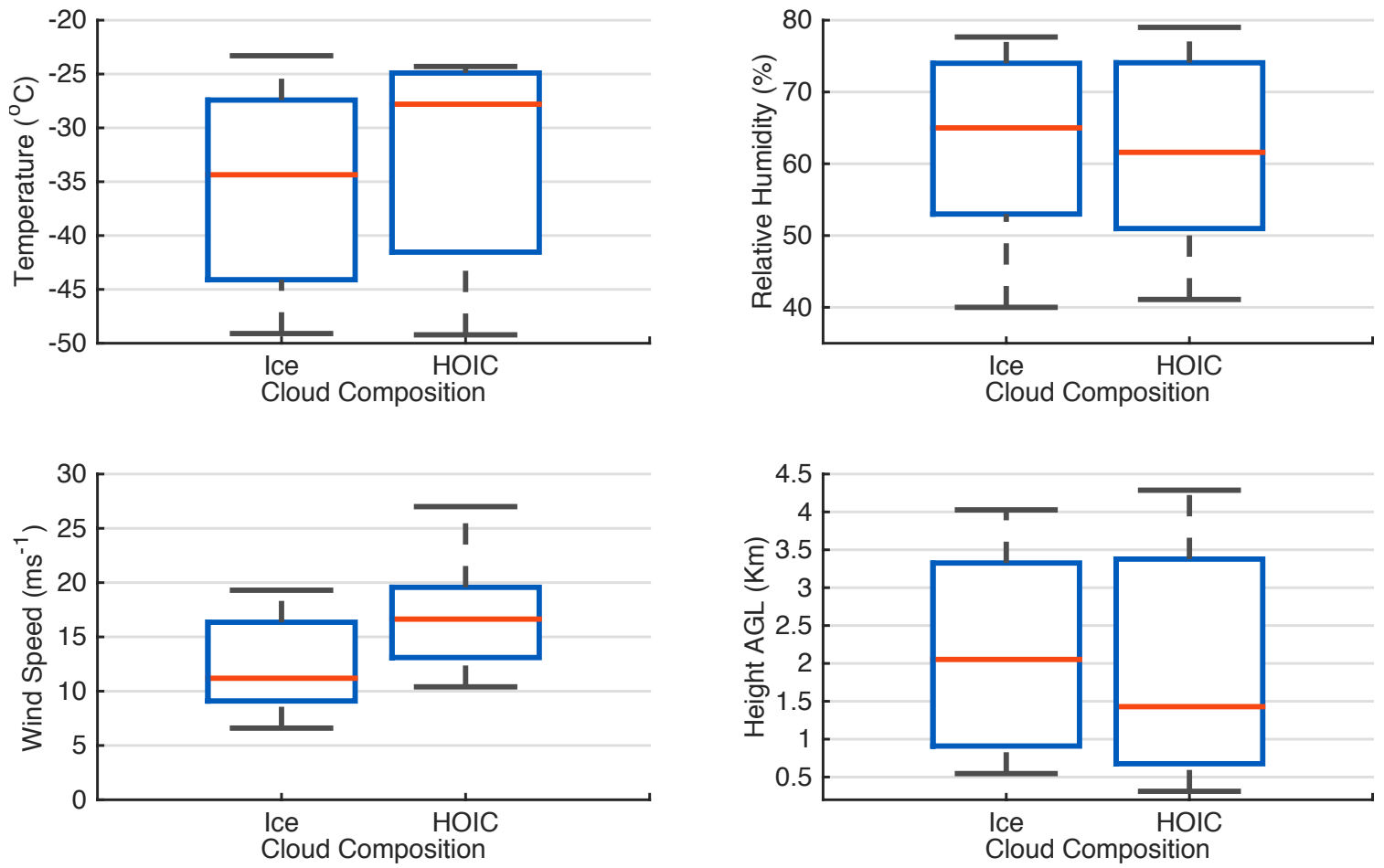

Figure 8. Distributions of temperature, RH, horizontal wind speed and height over which HOIC occurred in cirrus cloud compared with that of ice assumed to be randomly oriented. Boxes include the $25^{\text {th }}$ to $75^{\text {th }}$ percentiles and whiskers extend to the $10^{\text {th }}$ and $90^{\text {th }}$ percentiles. 
Atmos. Chem. Phys. Discuss., doi:10.5194/acp-2016-1134, 2017

Manuscript under review for journal Atmos. Chem. Phys.

Discussion started: 16 March 2017

(c) Author(s) 2017. CC-BY 3.0 License.

\section{(c) (1)}
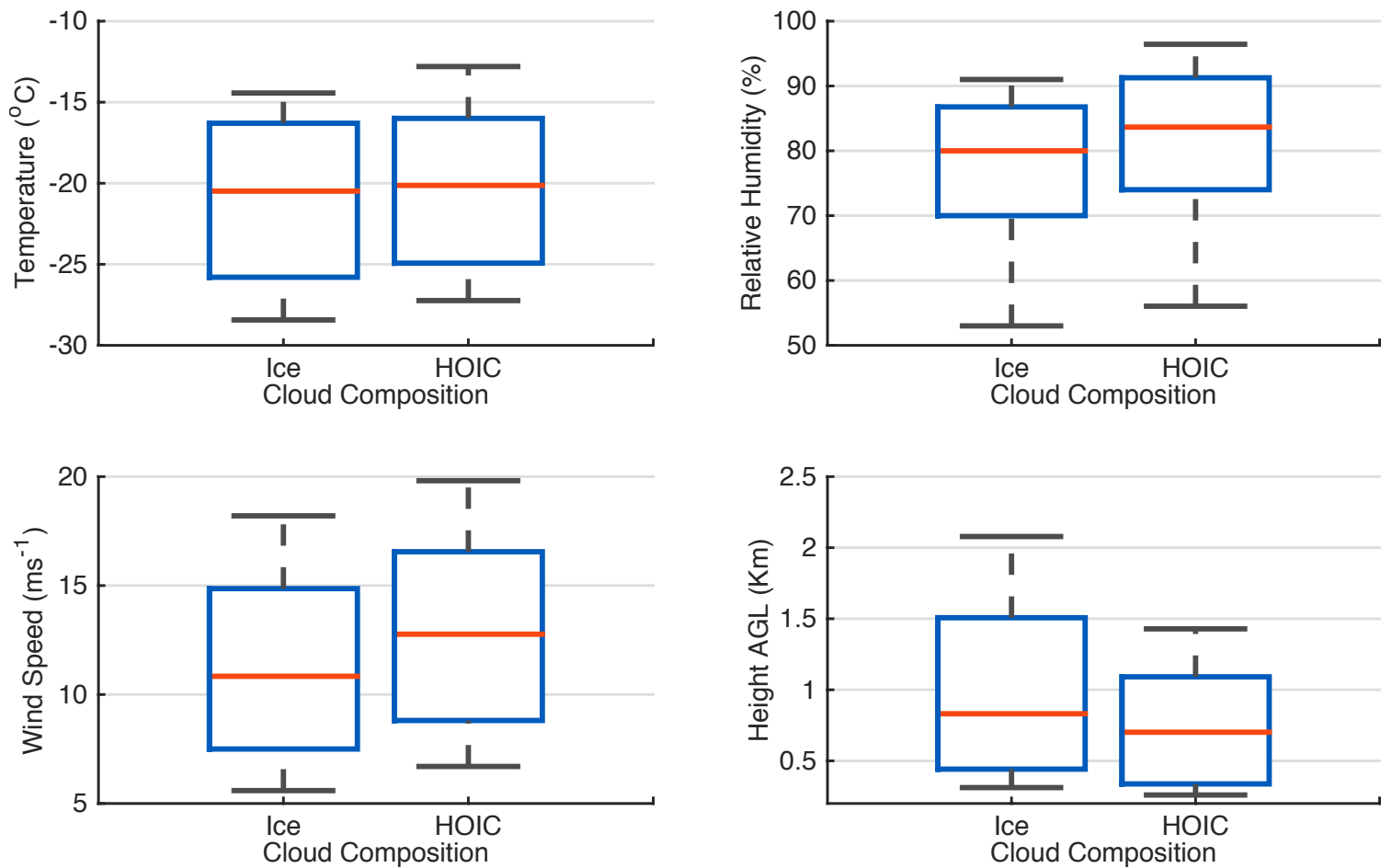

Figure 9 Distributions of temperature, RH, horizontal wind speed and height over which HOIC occurred in stratiform cloud compared with that of liquid and other ice, assumed to be randomly oriented. Boxes include the $25^{\text {th }}$ to $75^{\text {th }}$ percentiles and whiskers extend to the $10^{\text {th }}$ and $90^{\text {th }}$ percentiles. 
Atmos. Chem. Phys. Discuss., doi:10.5194/acp-2016-1134, 2017

Manuscript under review for journal Atmos. Chem. Phys.

Discussion started: 16 March 2017

(c) Author(s) 2017. CC-BY 3.0 License.
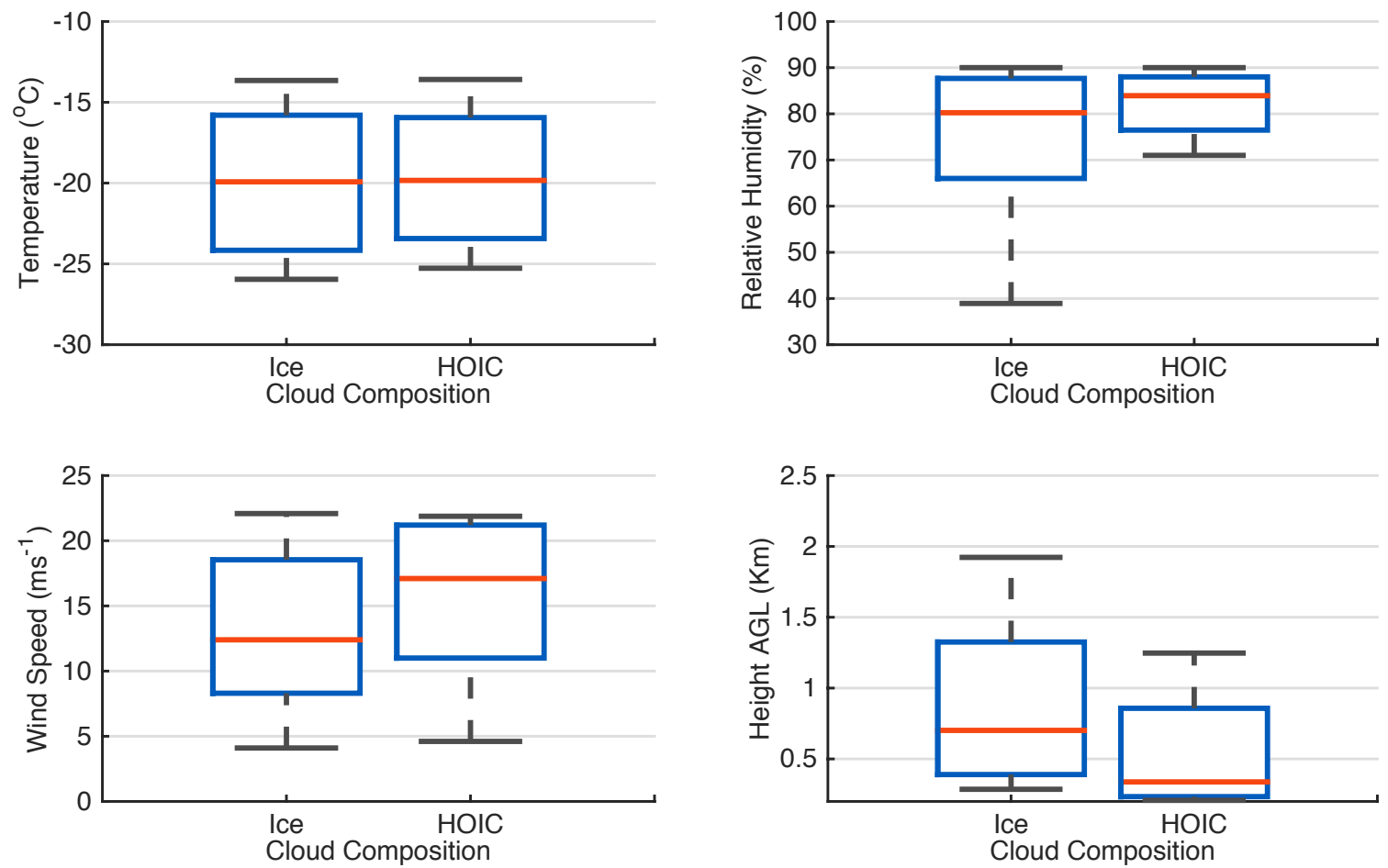

Figure 10. Distributions of temperature, $\mathrm{RH}$, horizontal wind speed and height over which HOIC occurred in cirrus cloud compared with that of ice assumed to be randomly oriented. Boxes include the $25^{\text {th }}$ to $75^{\text {th }}$ percentiles and whiskers extend to the $10^{\text {th }}$ and $90^{\text {th }}$ percentiles. 
Atmos. Chem. Phys. Discuss., doi:10.5194/acp-2016-1134, 2017

Manuscript under review for journal Atmos. Chem. Phys.

Discussion started: 16 March 2017

(c) Author(s) 2017. CC-BY 3.0 License.
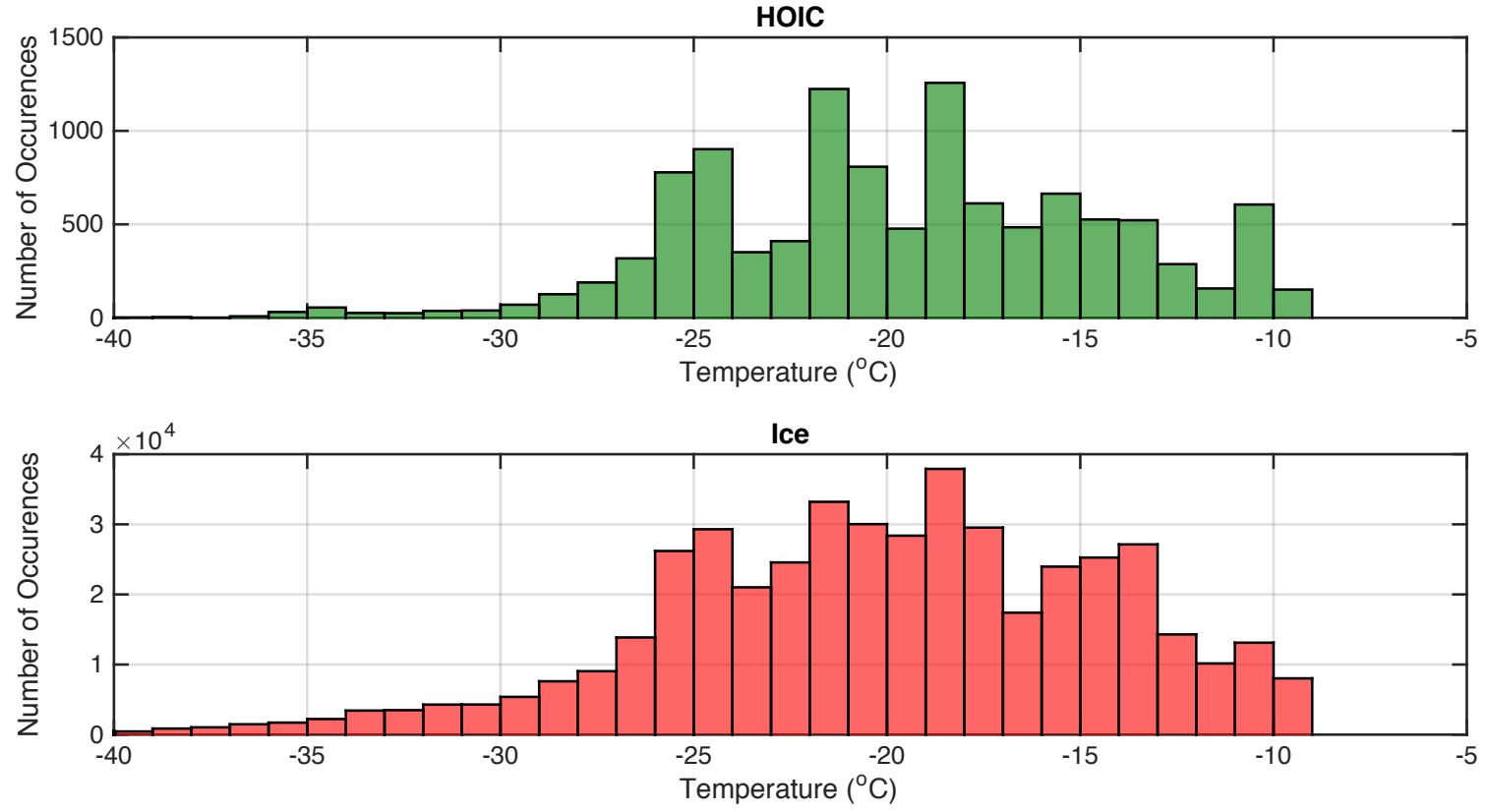

Figure 11 Histograms of temperature falling/precipitated HOIC and falling/precipitated ice (assumed to be randomly oriented). 
Atmos. Chem. Phys. Discuss., doi:10.5194/acp-2016-1134, 2017

Manuscript under review for journal Atmos. Chem. Phys.

Discussion started: 16 March 2017

(c) Author(s) 2017. CC-BY 3.0 License.

Table 1. Criteria used for the classification of clear sky and cloud properties.

\begin{tabular}{|c|c|c|c|c|c|}
\hline \multirow[b]{2}{*}{$\begin{array}{l}\text { Atmospheric } \\
\text { Condition }\end{array}$} & \multicolumn{5}{|l|}{ Criteria } \\
\hline & $\begin{array}{l}\text { Backscatter } \\
\text { Ratio }\end{array}$ & Depolarization & $\begin{array}{l}\text { Depolarization } \\
\text { Error }\end{array}$ & $\begin{array}{l}\text { Combined } \\
\text { Diattenuation }\end{array}$ & $\begin{array}{l}\text { Combined } \\
\text { Diattenuation } \\
\text { Error }\end{array}$ \\
\hline No Cloud & $<26$ & $<0.015$ & $<0.1$ & $\mathrm{~N} / \mathrm{A}$ & $\mathrm{N} / \mathrm{A}$ \\
\hline Liquid Cloud & $\geq 26$ & $<0.11$ & $<0.1$ & $<0.005$ & $<0.001$ \\
\hline Ice Cloud (ROIC) & $\geq 26$ & $\geq 0.11$ & $<0.1$ & $\geq 0.005$ & $<0.001$ \\
\hline HOIC & $\geq 26$ & $\geq 0.11$ & $<0.1$ & $<0.005$ & $<0.001$ \\
\hline
\end{tabular}


Atmos. Chem. Phys. Discuss., doi:10.5194/acp-2016-1134, 2017

Manuscript under review for journal Atmos. Chem. Phys.

Discussion started: 16 March 2017

(c) Author(s) 2017. CC-BY 3.0 License.

Table 2. Statistical significance of differences between the conditions under which HOIC occur in cirrus cloud and the conditions under which ice occurs in cirrus cloud. Conditions tested include temperature (T) relative humidity (RH), horizontal wind Speed $\left(\mathrm{W}_{\mathrm{s}}\right)$ and height AGL (H).) The test result at the $95 \%$ level (h) is reported with 1 denoting a rejection of the null hypothesis and 0 denoting a failure to reject the null hypothesis.

\begin{tabular}{|c|c|c|c|c|}
\hline \multicolumn{5}{|c|}{ Cirrus - Ice vs HOIC } \\
\hline \multirow[b]{2}{*}{$\begin{array}{l}\text { Statistical } \\
\text { Properties }\end{array}$} & \multicolumn{4}{|c|}{ Variable Tested } \\
\hline & $\mathrm{T}$ & RH & $\mathrm{W}_{\mathrm{s}}$ & $\mathrm{H}$ \\
\hline Mean Ice $_{\text {Ice }}$ & $-36^{\circ} \mathrm{C}$ & $60 \%$ & $13 \mathrm{~ms}^{-1}$ & $2.25 \mathrm{~km}$ \\
\hline Mean $_{\text {HOIC }}$ & $-33^{\circ} \mathrm{C}$ & $61 \%$ & $17 \mathrm{~ms}^{-1}$ & $2.13 \mathrm{~km}$ \\
\hline $\mathbf{h}$ & 1 & 0 & 1 & 1 \\
\hline
\end{tabular}


Atmos. Chem. Phys. Discuss., doi:10.5194/acp-2016-1134, 2017

Manuscript under review for journal Atmos. Chem. Phys.

Discussion started: 16 March 2017

(c) Author(s) 2017. CC-BY 3.0 License.

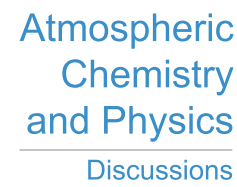

(c) (1)

Table 3. Statistical significance of differences between the conditions under which HOIC occur in stratiform cloud and the conditions under which ice occurs in stratiform cloud. Conditions tested include temperature (T) relative humidity (RH), horizontal wind speed (Ws) and height AGL (H). The test result at the 95\% level (h) is reported with 1 denoting a rejection of the null hypothesis and $\mathbf{0}$ denoting a failure to reject the null hypothesis.

\begin{tabular}{|l|l|l|l|l|}
\hline \multicolumn{5}{|l|}{ Stratiform - Ice vs HOIC } \\
\hline & \multicolumn{4}{l|}{ Variable Tested } \\
\hline $\begin{array}{l}\text { Statistical } \\
\text { Properties }\end{array}$ & $\mathrm{T}$ & $\mathrm{RH}$ & $\mathrm{W}$ & $\mathrm{H}$ \\
\hline Mean $_{\text {Ice }}$ & $-21^{\circ} \mathrm{C}$ & $74 \%$ & $12 \mathrm{~ms}^{-1}$ & $1.11 \mathrm{~km}$ \\
\hline Mean $_{\text {Hогс }}$ & $-20^{\circ} \mathrm{C}$ & $78 \%$ & $13 \mathrm{~ms}^{-1}$ & $0.85 \mathrm{~km}$ \\
\hline $\mathbf{h}$ & $\mathbf{1}$ & $\mathbf{1}$ & $\mathbf{1}$ & $\mathbf{1}$ \\
\hline
\end{tabular}


Atmos. Chem. Phys. Discuss., doi:10.5194/acp-2016-1134, 2017

Manuscript under review for journal Atmos. Chem. Phys.

Discussion started: 16 March 2017

(c) Author(s) 2017. CC-BY 3.0 License.

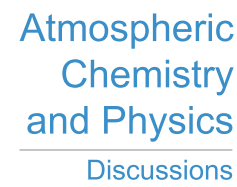

(c) (1)

Table 4 Statistical significance of differences between the conditions under which HOIC occur in stratiform cloud and the conditions under which liquid water occurs in stratiform cloud. Conditions tested include temperature (T) relative humidity (RH), horizontal wind speed (Ws) and height AGL (H). The test result at the $95 \%$ level (h) is reported with 1 denoting a rejection of the null hypothesis and 0 denoting a failure to reject the null hypothesis.

\begin{tabular}{|c|c|c|c|c|}
\hline \multicolumn{5}{|c|}{ Stratiform - Liquid vs HOIC } \\
\hline \multirow[b]{2}{*}{$\begin{array}{l}\text { Statistical } \\
\text { Properties }\end{array}$} & \multicolumn{4}{|c|}{ Variable Tested } \\
\hline & $\mathrm{T}$ & $\mathrm{RH}$ & $\mathrm{W}_{\mathrm{s}}$ & $\mathrm{H}$ \\
\hline Mean $_{\text {Liquid }}$ & $-18^{\circ} \mathrm{C}$ & $82 \%$ & $12 \mathrm{~ms}^{-1}$ & $0.70 \mathrm{~km}$ \\
\hline Mean $_{\text {HOIC }}$ & $-20^{\circ} \mathrm{C}$ & $78 \%$ & $13 \mathrm{~ms}^{-1}$ & $0.85 \mathrm{~km}$ \\
\hline h & 1 & 1 & 1 & 1 \\
\hline
\end{tabular}


Atmos. Chem. Phys. Discuss., doi:10.5194/acp-2016-1134, 2017

Manuscript under review for journal Atmos. Chem. Phys.

Discussion started: 16 March 2017

(c) Author(s) 2017. CC-BY 3.0 License.

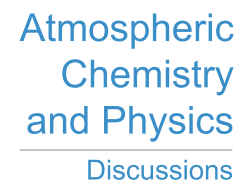

(c) (1)

Table 5 Statistical significance of differences between the conditions under which HOIC precipitate/fall from cloud and the conditions under which ice precipitate/fall from cloud. Conditions tested include temperature (T) relative humidity (RH), horizontal wind Speed (Ws) and height AGL (H). The test result at the $95 \%$ level (h) is reported with 1 denoting a rejection of the null hypothesis and 0 denoting a failure to reject the null hypothesis.

\begin{tabular}{|c|c|c|c|c|}
\hline \multicolumn{5}{|c|}{ Falling - Ice vs HOIC } \\
\hline & \multicolumn{4}{|c|}{ Variable Tested } \\
\hline $\begin{array}{c}\text { Statistical } \\
\text { Properties }\end{array}$ & $\mathrm{T}$ & $\mathrm{RH}$ & $\mathrm{W}_{\mathrm{s}}$ & $\mathrm{H}$ \\
\hline Mean $_{\text {Ice }}$ & $-20.4^{\circ} \mathrm{C}$ & $72 \%$ & $14 \mathrm{~ms}^{-1}$ & $1.02 \mathrm{~km}$ \\
\hline Mean $_{\text {HOIC }}$ & $-19.7^{\circ} \mathrm{C}$ & $80 \%$ & $16 \mathrm{~ms}^{-1}$ & $0.65 \mathrm{~km}$ \\
\hline $\mathbf{h}$ & $\mathbf{1}$ & $\mathbf{1}$ & $\mathbf{1}$ & $\mathbf{1}$ \\
\hline
\end{tabular}

